\title{
Miscellaneous Pulmonary Disease
}

\author{
Contents \\ INTRODUCTION \\ Hypersensitivity Pneumonitis \\ Drug Reaction and Hemorrhage \\ Other Pulmonary Diseases \\ SugGeSTED READINGS \\ LETTERS
}

\section{INTRODUCTION}

In this chapter, a series of cases is presented that have provoked significant thought on the part of the consulting and consulted pathologists. Most of these cases don't fall neatly into the context of other chapters in this volume. A number of these cases illustrate patterns of pulmonary disease that are not diagnostic and challenge the pathologist to offer an intelligent differential diagnosis. A brief discussion of some of these relevant diagnoses follows.

\section{HYPERSENSITIVITY PNEUMONITIS}

Sometimes termed extrinsic allergic alveolitis, hypersensitivity pneumonitis exhibits bronchiolitis, lymphohistiocytic infiltrate, eosinophils, and multinucleated histiocytes. An offending agent often is never identified. Many cases have the histology of a nonspecific interstitial pneumonitis (NSIP) if no bronchiolitis or giant cells are present.

\section{DRUG REACTION AND HEMORRAGE}

Drug reactions (6764) depend on the drug and may be chronic or acute, interstitial or alveolar, and marked or slight. There may or may not be eosinophils, pleuritis, bronchiolitis, or granulomatous inflammation depending on the drug. Because of the common use of amiodarone and because of some more specific features, amiodarone constitutes a special case. Usual interstitial pneumonitis (UIP) with amiodarone effect must be considered in the differential diagnosis.

The most common differential diagnosis for pulmonary capillaritis is an acute bacterial or viral pneumonia that has caused extensive hemorrhage without capillaritis. Filling of the alveoli and bronchioles with neutrophils and microabscesses suggest infection. Hyaline membranes suggest viral infection, as was illustrated in Chapter 4. Hyaline 
membranes also raise the possibility of diffuse alveolar damage (DAD), which occasionally exhibits more blood than hyaline membranes or atypia of pneumocytes and fibroblasts.

A bleeding diathesis leaves no telltale histological finding in the lung unless one also finds an intravascular leukemia that might be causing it. Arteriovenous malformations are generally difficult to identify unless angiography localizes them precisely. Even then, pulmonary arteriovenous malformations may destroy themselves when they rupture. There may be no way to prove that blood in an open lung biopsy has been aspirated from a proximal source, but often aspirated blood fills one lobule entirely and the adjacent lobule not at all. This is because blood is draining into one terminal bronchiole that bifurcates downward relative to gravity but does not enter the next terminal bronchiole that bifurcates upward relative to gravity.

Pulmonary hemorrhage occurs in a variety of pulmonary-renal syndromes. Some are well characterized, such as Goodpasture's syndrome (anti-basement membrane antibody disease) and IgA nephropathy. Other pulmonary bleeding may be poorly characterized and idiopathic. In our experience, a leukocytoclastic capillaritis is not recognized in the lung in Goodpasture's syndrome even when there is extensive hemorrhage.

Hemosiderosis (6911) has more fibrosis relative to inflammation than UIP. Hemosiderosis may be diffuse or patchy. Small amounts of hemosiderin are occasionally seen in UIP. In cases of moderate amount, distinction may not be possible. Hemosiderosis secondary to mitral disease or to primary veno-occlusive disease is associated with changes of venous hypertension.

Idiopathic pulmonary hemosiderosis (IPH) is a diagnosis best avoided if at all possible. Although the histological features of interstitial fibrosis and extensive hemosiderin are easy to recognize, the pathological diagnosis does not have a consistent clinical presentation or natural history. There are probably several causes of the idiopathic form of the disease, one of which is a previous capillaritis and hemorrhage. IPH in these cases is the chronic sequel to the acute hemorrhage. Diagnoses of Wegener's granulomatosis (WG) and Goodpasture's syndrome have been established during later episodes of acute pulmonary hemorrhage in patients with a prior diagnosis of IPH.

\section{Amiodarone Pneumonitis}

- Drug-induced phospholipidosis

- Vacuolated macrophages and pneumocytes

- Birefringent particles

- Lamellar inclusions

- Interstitial pneumonitis (R/O UIP)

- Hyaline membranes

- Bronchiolitis

- ? reversible, ? honeycomb fibrosis

\section{Pulmonary Hemorrhage in Open Lung Biopsy: Causes}

- Operative effect

- Aspiration

- Bleeding diathesis

- Arteriovenous malformation

- DAD

- Infective pneumonia 
- Goodpasture's disease

- IPH

- Capillaritis

\section{Blood in Lung: Clues That It May Be Illusory}

- Neutrophils around pleural venules

- One lobule involved but not another

- Intervening alveoli atelectatic

- Alveoli not expanded

- No hemosiderin

\section{OTHER PULMONARY DISEASES}

Asbestosis in late stage is primarily fibrosis, but in early stage, an interstitial lymphocytic infiltrate may be marked. Asbestosis in early stage may be accentuated around respiratory bronchioles and beneath the pleura. This localization is not part of UIP. One or more asbestos bodies per slide exclude UIP. Differentiation of asbestosis (6867) from silicatosis (6917) is based on the strong birefringence of silicates, which result from the combination of silicon dioxide with one or more cations, usually magnesium, calcium, and aluminum. Furthermore, ferruginated silicates differ in morphology from asbestos bodies, being broader, shorter, plate-like, and more irregular than asbestos bodies.

Occasional patients have a nonscarring lymphocytic interstitial infiltrate of moderate degree without granulomas and without accentuation around bronchioles. This entity may be seen primarily in children, where the clinical course has been benign and the children have recovered. It is possible that some cases represent viral stimulation of the immune system in the lung in a manner comparable to follicular bronchiolitis, which is the usual differential diagnosis clinically. Other cases in the literature may represent abnormal immature lung, in part or in whole.

UIP, desquamative interstitial pneumonitis (DIP), and lymphocytic interstitial pneumonitis (LIP) all occur in childhood. The same essential histological criteria are applied as in adults. However, the clinical significance of these diagnoses in children is less clear than in adults.

A few congenital anomalies of lung reviewed here reflect some diagnostic challenges to which the pathologist may be confronted. Congenital pulmonary lymphangiectasia (6667), a usually fatal disorder in a neonate, is characterized microscopically by cystic dilatation of lymphatic vessels in interlobular septa and fanning out in the subpleural region of an entire lung or, rarely, a single lobe. The endothelial cells, which line the dilated vessels, may be lined by a loose myxoid or dense connective tissue. This entity is distinguished from interstitial pulmonary emphysema, in which dilated spaces lacking a cellular lining are limited to interlobular spaces.

Congenital cystic adenomatoid malformations, recently given the new name of congenital pulmonary airway malformations (CPAMs), are subclassified into five separate anomalies originating from regions of the airway extending from the tracheobronchial segment to the distal acinar region. CPAM type 2 (6869), the intermediate cyst type, comprises 15-20\% of CPAMs and may be associated with other anomalies. Microscopically, these lesions consist of dilated bronchioles which lie "back to back" and are separated by structures that resemble irregular alveolar ducts. They have been seen in up to 
$50 \%$ of extralobar sequestrations, which are segments of pulmonary parenchyma which are isolated from the tracheobronchial tree, with separate visceral pleura and arterial blood supply ususally from a branch of the aorta. Extralobar sequestrations, except those with embedded CPAMs (6809), contain bronchioles, alveolar ducts, and alveoli which are uniformly dilated in uninflated specimens.

Mesenchymal hamartomatous nodules and cysts (4408) in the lungs can cause hemoptysis, pneumothorax, hemothorax, pleuritic chest pain, dyspnea of slight or moderate degree, or a combination of these signs and symptoms. They can be multifocal and bilateral. The nodules are composed of primitive mesenchymal cells subdivided into papillae by a plexus of small airways lined with respiratory epithelium. The nodules grow slowly in number and size over the years and apparently become cystic when they reach a diameter of about $1 \mathrm{~cm}$. The cysts have a cambium layer of mesenchymal cells and are lined with normal or metaplastic respiratory epithelium. In general, the disease has an indolent course. Malignant transformation has been noted in one case.

\section{SUGGESTED READINGS}

\section{Hypersensitivity Pneumonitis}

Sumi Y, Nagura H, Takeuchi M. Granulomatous lesions in the lung induced by inhalation of mold spores. Virch Arch 1994;424:661-668.

Coleman A, Colby TV. Histologic diagnosis of extrinsic allergic alveolitis. Am J Surg Pathol 1988;12:514-518.

Perry LP, Iwata M, Tazelaar HD, Colby TV, Yousem SA. Pulmonary mycotoxicosis: a clinicopathologic study of three cases. Mod Pathol 1998;11:432-436.

\section{Amiodarone Pneumonitis}

Jacobson W Stewart S, Gresham GA, Goddard MJ. Effect of amiodarone on the lung shown by polarized light microscopy. Arch Pathol Lab Med 1997;121:1269-1271.

Camus P, Lombard J-N, Perrichon M, et al. Bronchiolitis obliterans organising pneumonia in patients taking acebutolol or amiodarone. Thorax 1989;44:711-715.

Liu FL-W, Cohen RD, Downar E, Butany JW, Edelson JD, Rebuck AS. Amiodarone pulmonary toxicity: functional and ultrastructural evaluation. Thorax 1986;41:100-105.

Wilson BD, Lippmann ML. Pulmonary accumulation of amiodarone and N-desthylamiodarone. Relationship to the development of pulmonary toxicity. Am Rev Respir Dis 1990;141:1553-1558.

Dean PJ, Groshart KD, Porterfield JG, Iansmith DH, Golden EB Jr. Amiodarone-associated pulmonary toxicity. A clinical and pathologic study of eleven cases. Am J Clin Pathol 1987;87:7-13.

Myers JL, Kennedy JI, Plumb VJ. Amiodarone lung: pathologic findings in clinically toxic patients. Hum Pathol 1987;18:349-354.

\section{Hemorrhage}

Mark EJ, Ramirez JF. Pulmonary capillaritis and hemorrhage in patients with systemic vasculitis. Arch Pathol Lab Med 1985;109:413-418.

Yoshikawa Y, Watanabe T. Pulmonary lesions in Wegener's granulomatosis: a clinicopathologic study of 22 autopsy cases. Hum Pathol 1986;17:401-410.

Myers JL, Katzenstein A-LA. Microangiitis in lupus-induced pulmonary hemorrhage. Am J Clin Pathol 1986;85:552-556.

Mark EJ, Matsubara O, Tan-Liu NS, Fienberg R. The pulmonary biopsy in the early diagnosis of Wegener's (pathergic) granulomatosis: a study based on 35 open lung biopsies. Hum Pathol 1988;19:1065-1071.

Travis WD, Colby TV, Lombard C, Carpenter HA. A clinicopathologic study of 34 cases of diffuse pulmonary hemorrhage with lung biopsy confirmation. Am J Surg Pathol 1990;14:1112-1125.

Yoshimura N, Matsubara O, Tamura A, Kasuga T, Mark EJ. Wegener's granulomatosis. Associated with diffuse pulmonary hemorrhage. Acta Pathol Japonica 1992;42:657-661. 


\section{Other Pulmonary Diseases}

Gough J. Differential diagnosis in the pathology of asbestosis. Ann NY Acad Sci 1965;132:368-372.

Hourihane DO'B, McCaughey WTE. Pathological aspects of asbestosis. Postgrad Med J 1966;42:613-622.

Churg A, Warnock ML, Green N. Analysis of the cores of ferruginous (asbestos) bodies from the general population. II. True asbestos bodies and pseudoasbestos bodies. Lab Invest 1979;40:31-38.

Lerman Y, Ribak J, Selikoff IJ. Hazards of lung biopsy in asbestos workers. Br J Indust Med 1986;43:165169.

Bellis D, Andrion A, Delsedime L, Mollo F. Minimal pathologic changes of the lung and asbestos exposure. Hum Pathol 1989;20:102-106.

Roggli VL, Benning TL. Asbestos bodies in pulmonary hilar lymph nodes. Mod Pathol 1990;3:513-517.

Gaensler EA, Jederlinic PJ, Churg A. Idiopathic pulmonary fibrosis in asbestos-exposed workers. Am Rev Respir Dis 1991;144:689-696.

Hammar SP. Controversies and uncertainties concerning the pathologic features and pathologic diagnosis of asbestosis. Sem Diag Pathol 1992;9:102-109.

Travis WD, Colby TV, Koss MN, Rosado-de-Christenson ML, Müller NL, King TE Jr. Non-neoplastic disorders of the lower respiratory tract. Wahington, DC. American Registry of Pathology and the Armed Forces Institute of Pathology, 2002;829.

Schroeder SA, Shannon DC, Mark EJ. Cellular interstitial pneumonitis in infants. A clinicopathological study. Chest 1992;101:1065-1069.

Moolman JA, Bardin PG, Rossouw DJ, Joubert JR. Cyclosporin as a treatment for interstitial lung disease of unknown aetiology. Thorax 1991;46:592-595.

Nicholson AG, Kim H, Corrin B, Bush A, du Bois RM, Sheppard MN. The value of classifying interstitial pneumonitis in childhood according to defined histological patterns. Histopathology 1998;33:203-211.

Katzenstein A-LA, Gordon LP, Oliphant M, Swender PT. Chronic pneumonitis of infancy. A unique form of interstitial lung disease occurring in early childhood. Am J Surg Pathol 1995;19:439-447.

Fan LL, Langston C. Chronic interstitial lung disease in children. Ped Pulmonol 1993;16:184-196.

Stocker JT. The respiratory tract. In: Pediatric Pathology, second edition, Stocker JT and Dehner LP, eds. Lippincott Williams and Wilkins, Philadelphia: 2001, pp. 445-518.

Brown M, Pysher T, Coffin CM. Lymphangioma and congenital pulmonary lymphangiectasis: a histologic, immunohistochemical, and clinicopathological comparison. Mod Pathol 1999;12:569-575.

Stocker JT, Madewall JE, Drake RM. Congenital cystic adenomatoid malformation of the lung. Classification and morphologic spectrum. Hum Pathol 1977;8:155-171.

Stocker JT. Congenital pulmonary airway malformation - a new name for and an expanded classification of congenital cystic adenomatoid malformation of the lung. Histopathology 2002;41(suppl. 2):424-430.

Stocker JT, Kagan-Hallet K. Extralobar pulmonary sequestration: analysis of 15 cases. Am J Clin Pathol 1979;72:917-925.

Conran RM, Stocker JT. LExtralobar sequestration with frequently associated congenital cystic adenomatoid malformation, type 2: report of 50 cases. Pediatr Dev Pathol 1999;2:454-463.

Mark EJ. Mesenchymal cystic hamartoma of the lung. N Engl J Med1986;315:1255-1259. 


\section{LETTERS}

\section{Case 7010}

Diagnosis: Lung, open biopsy: Lymphohistiocytic inflammation, moderate, with peribronchiolar accentuation and scattered neutrophils in bronchioles, consistent with hypersensitivity reaction.

I essentially agree with your interpretation of hypersensitivity pneumonitis vs LIP. In my view LIP is a lymphoproliferative disorder, whereas in this case there are the added components of histiocytic inflammation around alveoli, neutrophils in bronchioles, and a few small aggregates of histiocytes. These features all suggest hypersensitivity pneumonitis, even though eosinophils and distinct granulomatous inflammation are lacking. The clinical history is also consistent with either of the two proposed clinical interpretations, but more in keeping with the history of intermittent seasonal disease. Lymphocytic hyperplasia or inflammation (Giemsa stain) also can occur with autoimmune and collagen-vascular diseases, and I cannot exclude that interpretation, but the histiocytes favor hypersensitivity reaction. I generally do not use the term NSIP as an entity but rather as the process which has many attributes of UIP but is not diagnostic of same. The absence of significant scarring in this case excludes a firm diagnosis of UIP, and I would not make a diagnosis of NSIP in this case.

Thank you for referring this case in consultation. Please keep me informed of any follow-up and call if you have questions. With best wishes,

Sincerely yours, Eugene J. Mark, M.D. 


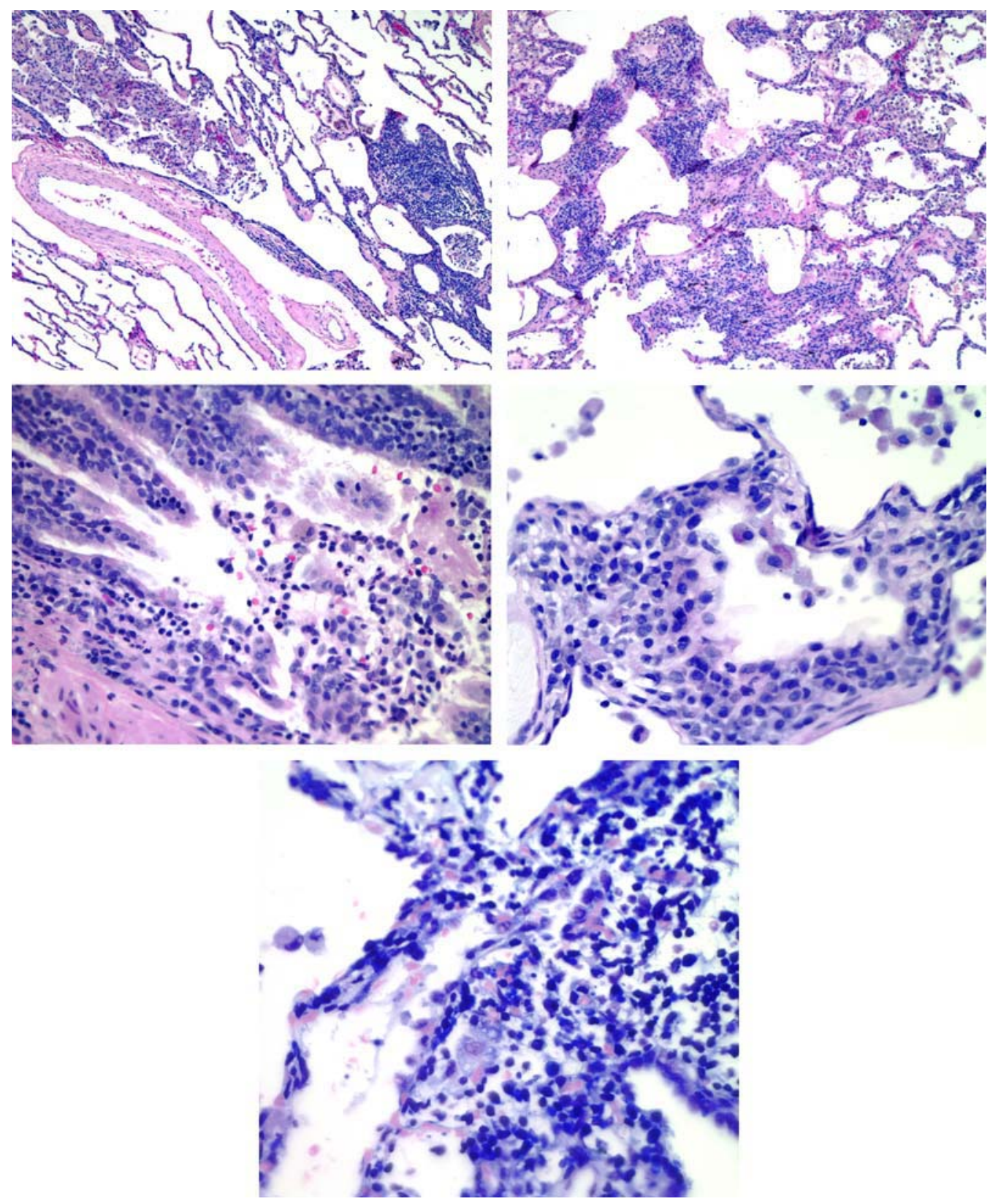

Case 7010 (Chapter 7 - Miscellaneous Pulmonary Disease) 


\section{Case 7170}

Diagnosis: Lung, open biopsy: Lymphohistiocytic and granulomatous inflammation, extensive, with refractile crystaline material in multinucelated histiocytes, ? hypersensitivity reaction, ? aspiration, ? other.

I have sectioned the four blocks of tissue which you provided and stained them with hematoxylin and eosin, elastic, trichrome, and periodic acid-Schiff. The majority of the lung is involved with a lymphohistiocytic infiltrate which is both interstitial and alveolar (trichrome stain). A small amount of bronchiolitis obliterans (BO) is present, but the pathology overall is not that bronchiolitis obliterans organizing pneumonia (BOOP). There are loosely aggregated histiocytes and several more compact aggregates of multinucleated histiocytes containing refractile and partially calcified material. Some histiocytes also have cholesterol clefts.

The etiology of this process is not clear. The crystalline material may represent aspiration, which could produce this histology. Hypersensitivity reaction is another possibility, but the absence of more extensive $\mathrm{BO}$ and the absence of eosinophils do not further support that interpretation. I cannot exclude a resolving infectious pneumonia, but I doubt it. No pus, compact granulomas of tuberculoid type, or necrosis are present. These features all serve to exclude an active infection. Acute sarcoidosis (Lofgren's syndrome) enters into the differential diagnosis. Elastic and trichrome stain show minimal fibrosis. The absence of temporal heterogeneity and the absence of advanced fibrosis such as subpleural honeycomb change are against UIP. To the degree that the process is principally cellular and minimally fibrotic, to that degree, one might hope for a favorable response to corticosteroid therapy.

Thank you for referring this case in consultation. Please keep me informed of any follow-up and call if you have questions. With best wishes,

Sincerely yours,

Eugene J. Mark, M.D. 

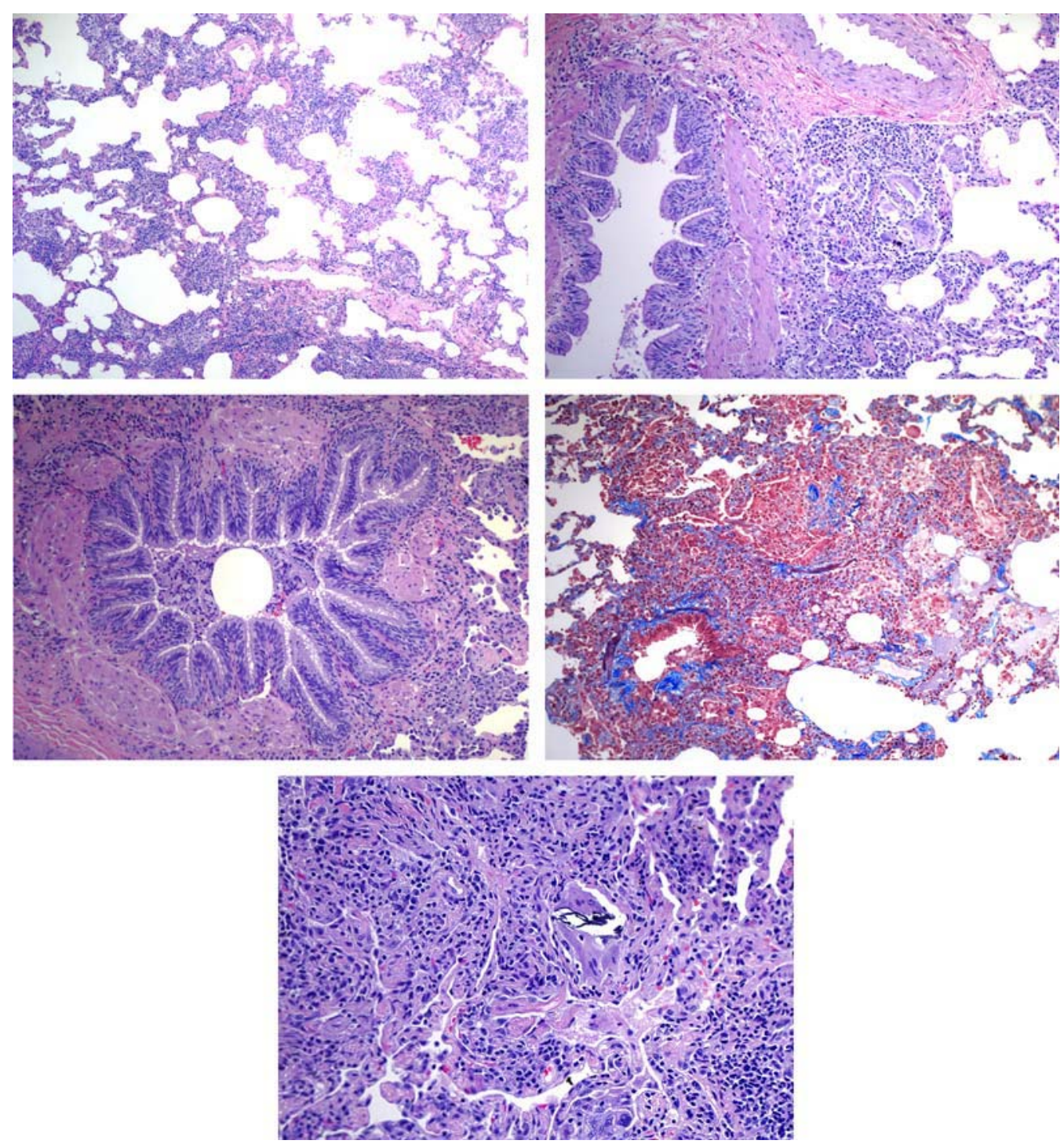

Case 7170 (Chapter 7 - Miscellaneous Pulmonary Disease) 


\section{Case 6687}

Diagnosis: Lung, open biopsy: Interstitial lymphocytic infiltrate with fibrin and vacuolated histiocytes and rare poorly formed granuloma, nonspecific, ? hypersensitivity pneumonitis, ? other.

The lymphohistiocytic infiltrate is well developed but unassociated with any significant old interstitial fibrosis or with active intra-alveolar organizing fibrosis. Multinucleated histiocytes and cholesterol clefts are present. Thus, the changes are not diagnostic of UIP (fibrosing alveolitis). Although I cannot exclude an early phase of that disease, I doubt that interpretation. The fibrin indicates active disease. The constellation of changes raises the possibility of a reaction to inhaled antigens or particles creating a hypersensitivity pneumonitis (extrinsic allergic alveolitis). This diagnosis would be more probable if bronchiolitis or eosinophils were present. There is a peribronchiolitis but no $\mathrm{BO}$ or organizing pneumonia $(\mathrm{OP})$. Other etiologic considerations include drug reaction, aspiration, the inflammatory phase of sarcoidosis with a "lymphocytic alveolitis" and no sarcoidal granulomas, or an unusual infection, such as psitticosis.

Thank you for referring this case in consultation. Please keep me informed of any follow-up. This is a confirmation of my telephone call. With best wishes,

Sincerely yours,

Eugene J. Mark, M.D. 

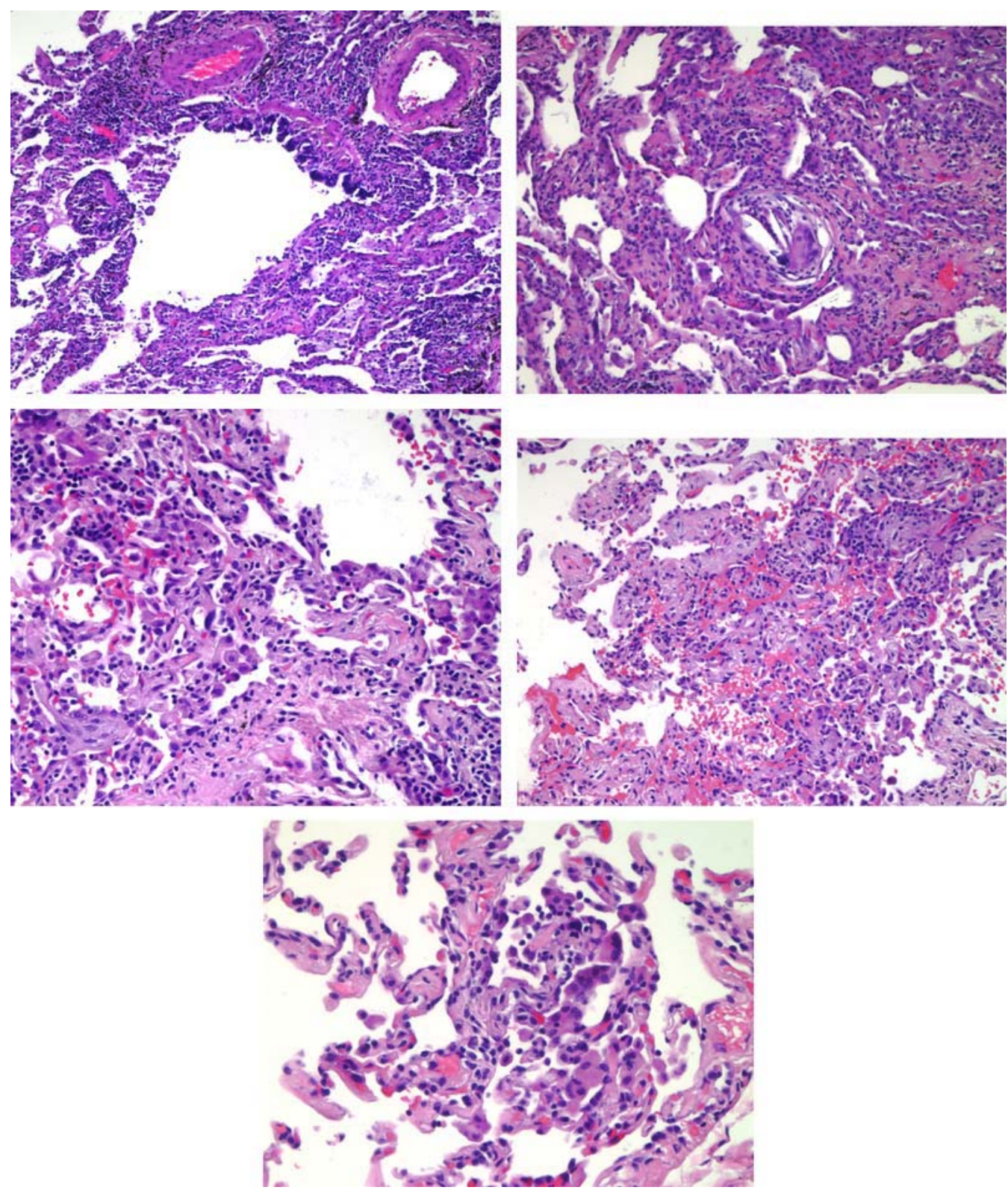

Case 6687 (Chapter 7 - Miscellaneous Pulmonary Disease) 


\section{Case 6924}

Diagnosis: Lung, open biopsy: Microgranulomatous peribronchiolitis and pneumonitis, ? hypersensitivity reaction, ? other.

The most specific facet of the biopsy are the histiocytic aggregates, which lie both in the adventitia of bronchioles and in the interstitium of alveolar walls. Descriptively this change can be termed microgranulomatous pneumonitis with a bronchiolar component. Microgranulomatous bronchiolitis has been associated with hypersensitivity reaction and collagen-vascular diseases. Extrinsic allergic alveolitis including that associated with aspergillus is one form of hypersensitivity reaction. Other cases remain enigmatic and idiopathic. I agree that the changes are not those of UIP. There is no old established interstitial fibrosis beneath the pleura, and the interstitial lymphocytic infiltrate is, for the most part, restricted to the granulomatous areas. I generally do not make a diagnosis of NSIP except to mean that a biopsy is not diagnostic for whatever reason. In the recent literature NSIP generally does not include granulomatous features. In this case, I have made a diagnosis emphasizing the granulomatous features and suggesting some possible etiologies.

Thank you for referring this case in consultation. Please keep me informed of any follow-up and call if you have questions. With best wishes,

Sincerely yours,

Eugene J. Mark, M.D. 

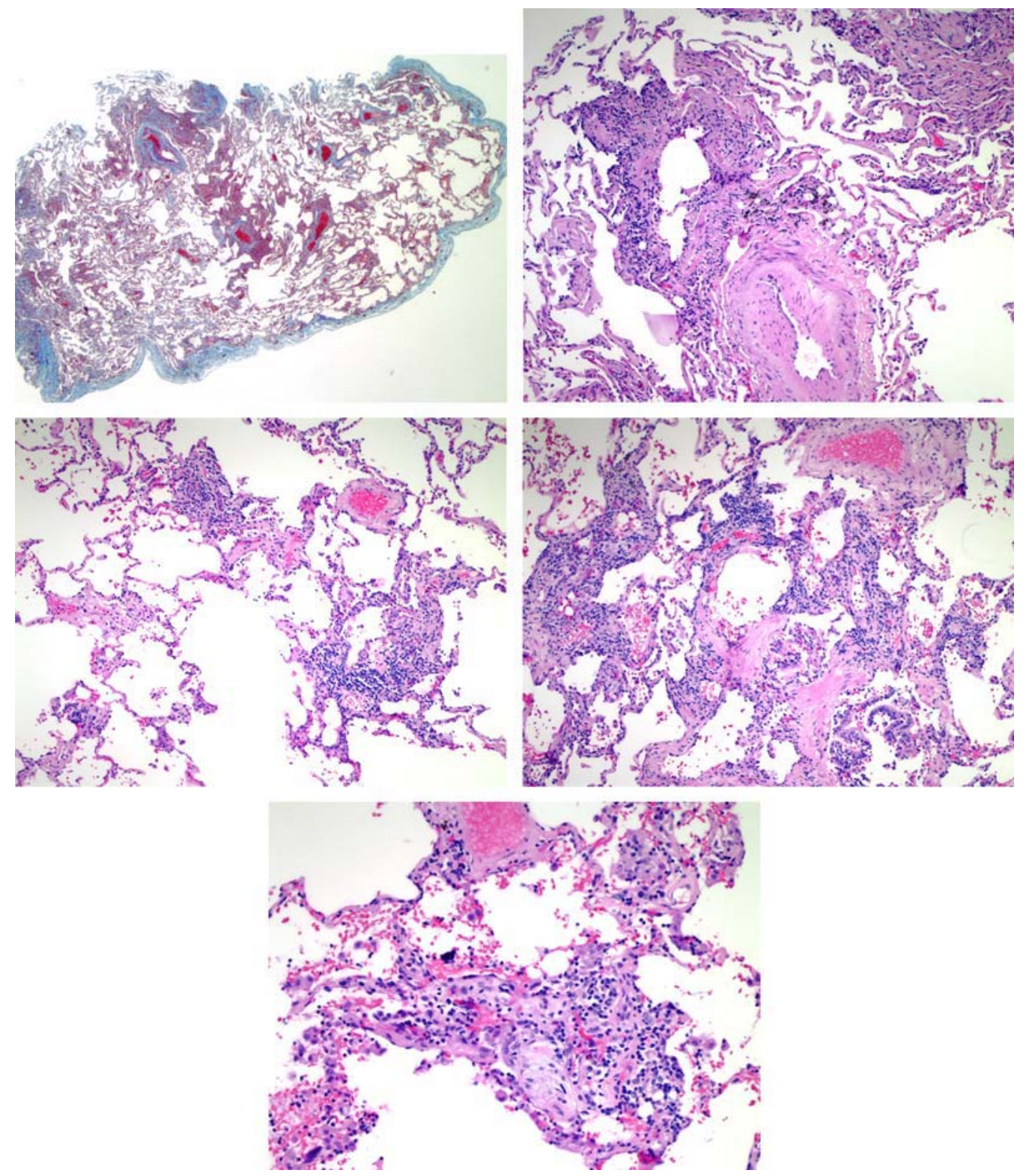

Case 6924 (Chapter 7 - Miscellaneous Pulmonary Disease) 


\section{Case 6950}

Diagnosis: Lung, open biopsy: Lymphocytic interstitial infiltrate and fibrinous pneumonia, etiology uncertain, ? hypersensitivity reaction, ? resolving infection, ? other.

I can describe this biopsy but cannot determine what has caused this process. The combination of hyperplastic lymphoid tissue around bronchioles with extension into alveolar walls simulates LIP, but that disease does not have the acute exudative character of alveolar fibrin and is not the correct interpretation. Hypersensitivity reaction would be further suspected if there were more bronchiolitis, but only a few bronchioles are occluded by fibrous plugs. However, an LIP-like change with edema has been seen in patients with hypersensitivity reaction. Another possibility is a slowly resolving unusual infection such as virus or mycoplasma or chlamydia. These agents might be further investigated by serologic or cultural studies. Collagen-vascular disease also can be considered because of the lymphoid hyperplasia and foci of chronic organizing pneumonia. I doubt toxic exposure. I am not sure whether or not the blood in the alveoli is real. Because of the extensive edema, some of it may represent leakage of capillaries. Because of the blood, we searched for a vasculitis, and we do find endothelial activation but no vascular necrosis, so vasculitis is not confirmed, and I doubt this interpretation.

Thank you for referring this case in consultation. Please keep me informed of any follow-up and call if you have questions. With best wishes,

Sincerely yours,

Eugene J. Mark, M.D. 

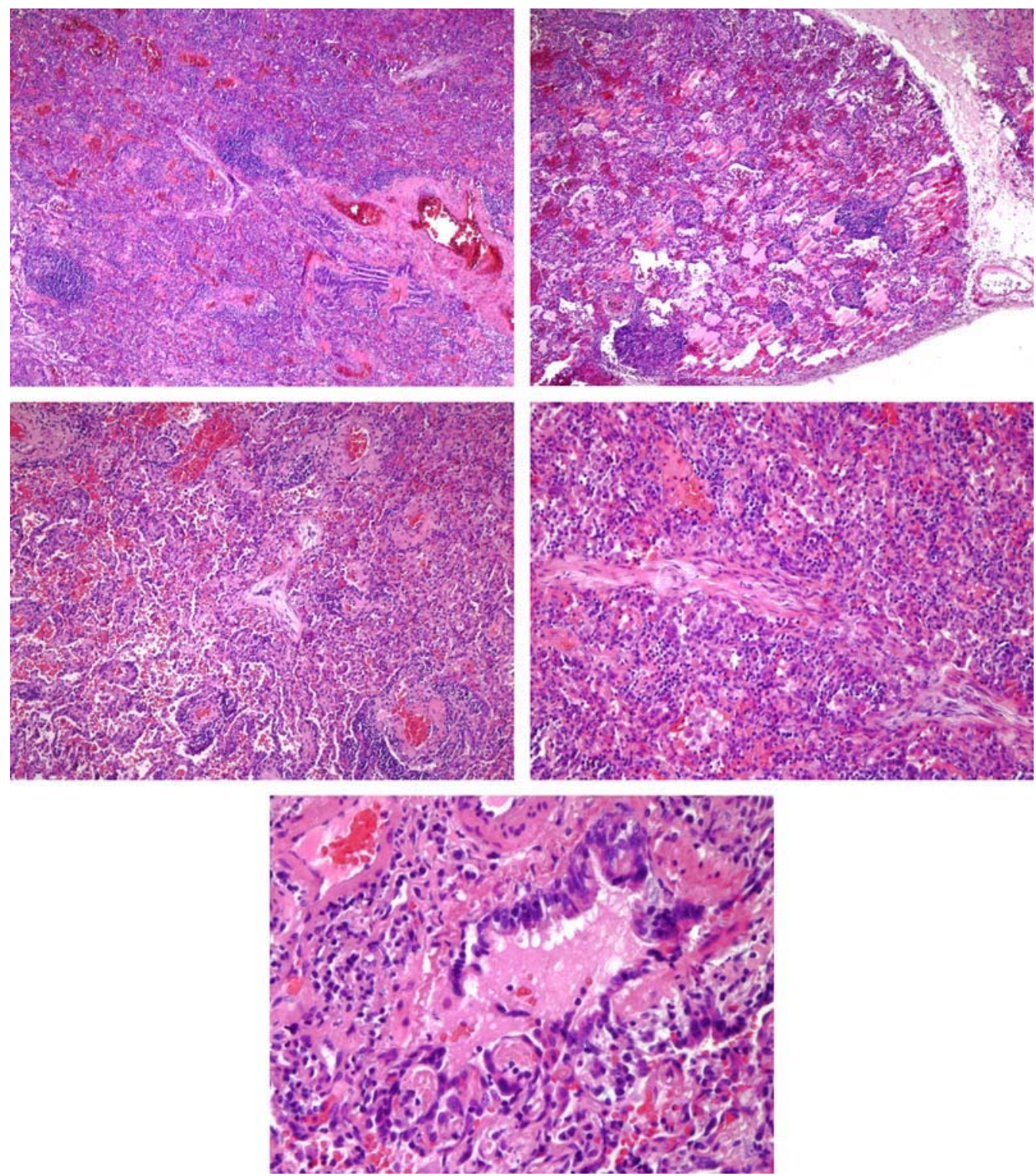

Case 6950 (Chapter 7 - Miscellaneous Pulmonary Disease) 


\section{Case 7013}

\section{Diagnosis: Lung, transbronchial biopsy: Histiocytic-eosinophilic infiltrate, type and significance uncertain.}

Aggregates of histiocytic cells vaguely resemble sarcoidal granulomas at low power, and multinucleated cells support a histiocytic origin, but the cells never form compact granulomas of sarcoidal type. The eosinophilic microabscesses are also unusual for sarcoid. The admixture of histiocytes and eosinophils raises the possibility of DIP or chronic eosinophilic pneumonia (CEP), but the histiocytic cells are not typical for either condition. The admixture of histiocytes and eosinophils and the positive stain for S-100 are consistent with eosinophilic granuloma (EG), but the large convoluted nuclei characteristic of Langerhans' cells are not apparent, and I doubt that this is EG. Occasionally histiocytic cells other than Langerhans' cells can stain for S-100, although staining here is very marked. The positive staining for S-100 made me think about metastatic malignant melanoma of the nevoid type, but this would not explain the eosinophils, and this process is not malignant in my opinion. In the etiologic differential diagnosis, I considered hypersensitivity reaction and schistosomiasis. This case is unusual and difficult in my opinion and in the opinion of several other senior pathologists in the department who have also reviewed the case. We do not know exactly what this biopsy represents.

Thank you for referring this case in consultation. Please keep me informed of any follow-up. Additional tissue will be necessary for more precise morphological diagnosis in my opinion. I have retained one slide stained with hematoxylin and eosin for our permanent teaching collection in pulmonary pathology and hereby return all of the remainder including all of your special studies.

Sincerely yours,

Eugene J. Mark, M.D. 

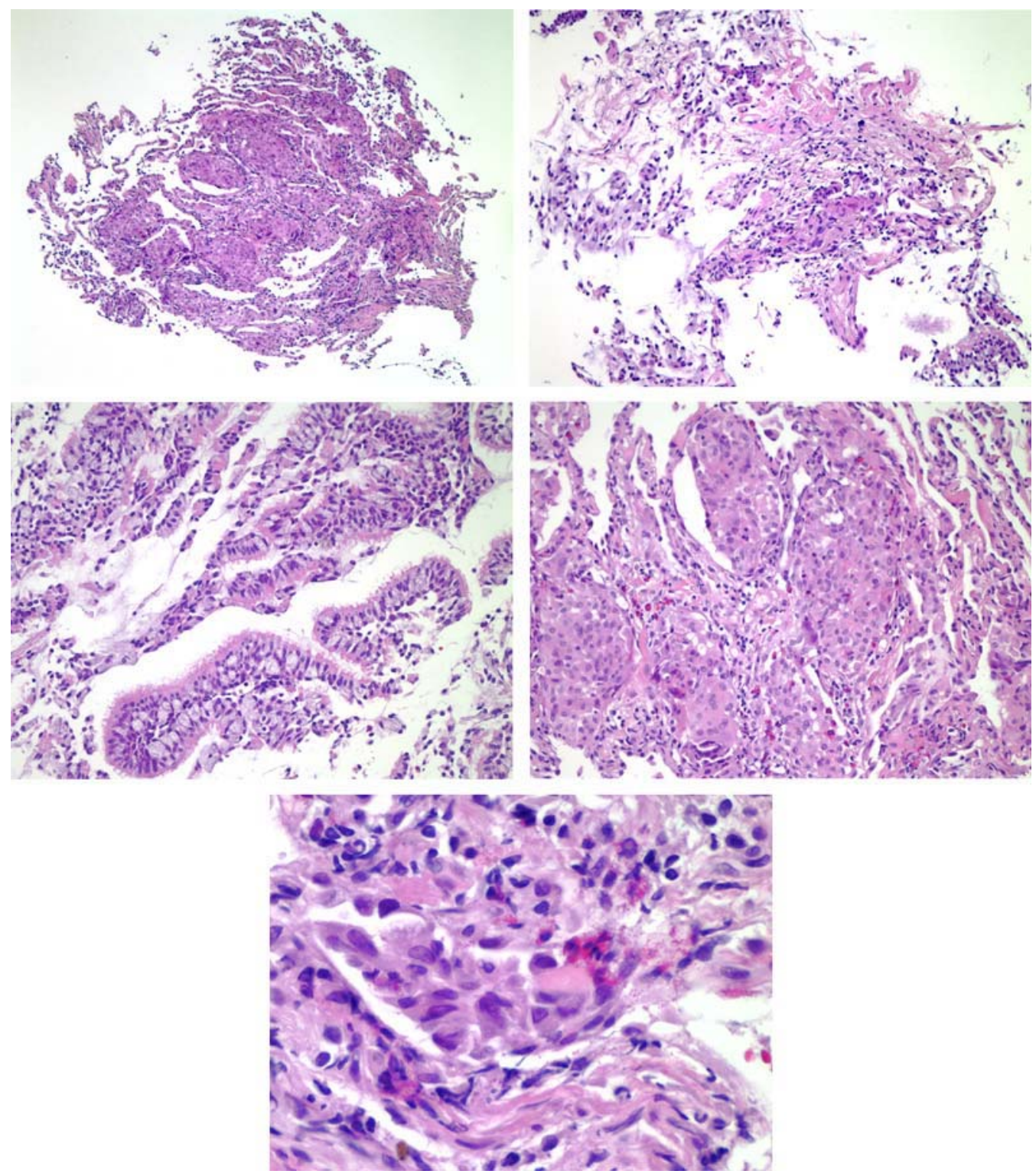

Case 7013 (Chapter 7 - Miscellaneous Pulmonary Disease) 


\section{Case 6493}

Diagnosis: Lung, open biopsy: Granulomatous pneumonitis with eosinophils.

A marked interstitial lymphohistiocytic infiltrate is associated with aggregated histiocytes sufficient to categorize this process as granulomatous. Eosinophils are present. Lymphocytes are prominent and include lymphoid nodules. Lymphoid hyperplasia of this degree can be seen in hypersensitivity pneumonitis, which I believe is the best etiologic diagnosis. This is in agreement with your suggestion of extrinsic allergic alveolitis, but I do not make the latter diagnosis pathologically because it is more a clinicopathological correlation requiring knowledge of what is extrinsic and what is allergic. Nevertheless, I suspect there is an antigenic cause for this patient's illness. I see no compact granulomas of sarcoidal type and do not favor sarcoidosis.

Thank you for referring this case in consultation. This is a confirmation of my telephone call. With best wishes,

Sincerely yours,

Eugene J. Mark, M.D. 

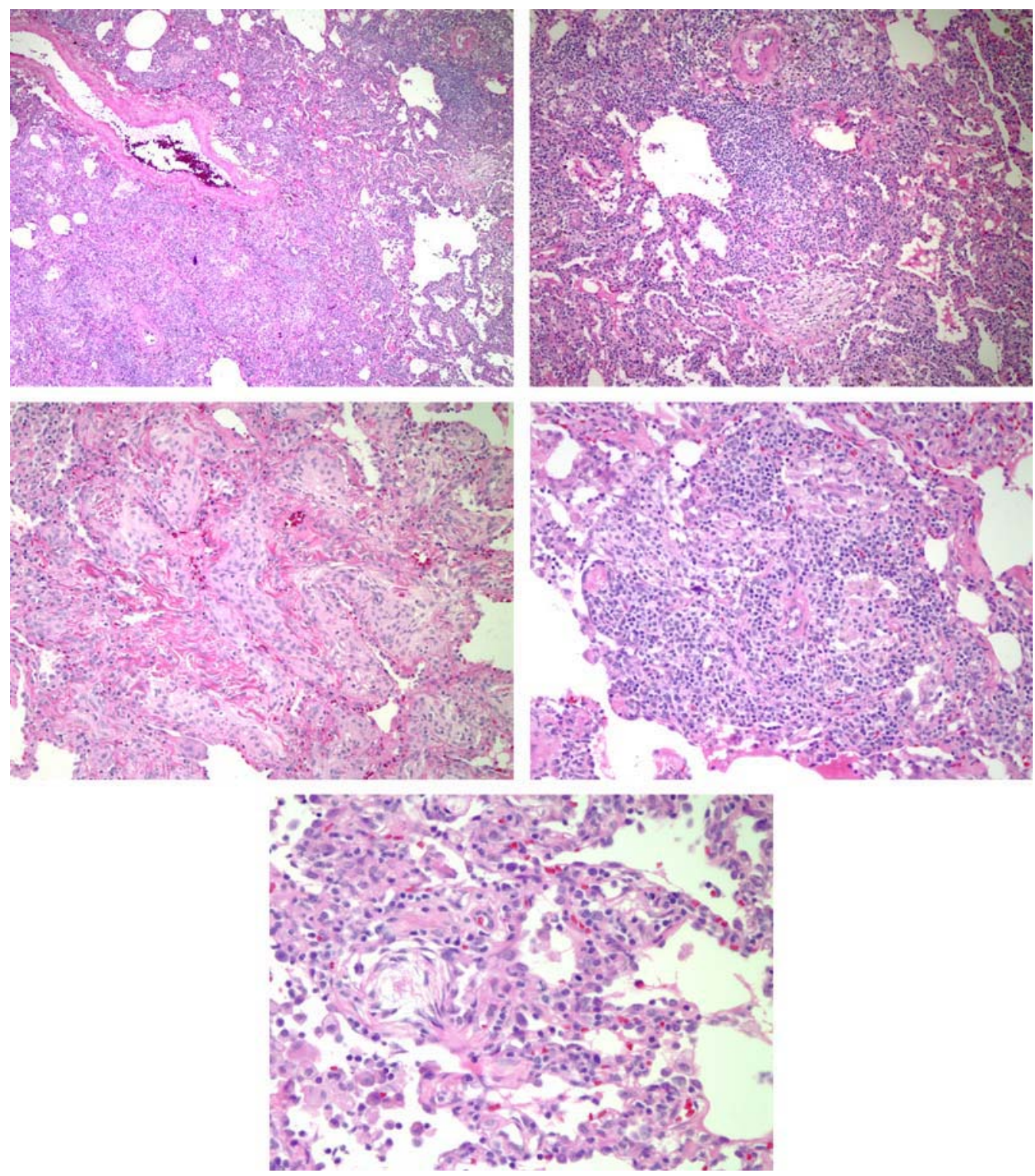

Case 6493 (Chapter 7 - Miscellaneous Pulmonary Disease) 


\section{Case 6890}

Diagnosis: Lung, transbronchial biopsy: Slight interstitial inflammation, vacuolated histiocytes, rare eosinophils and hypertrophic pneumocytes, nondiagnostic.

The specimen consists of approx 30 alveoli and an interlobular septum. A lymphohistiocytic infiltrate within the interstitium is associated with rare eosinophils. The differential diagnosis for these changes is broad and includes the interstitial pneumonitides, asthma, chronic eosinophilic pneumonia, bronchiolitis with patchy organizing pneumonia (BPOP), and other conditions. The vacuolated histiocytes probably represent an element of bronchiolar obstruction. There is probable slight fibrosis of lobular septa, but atelectasis and crush-effect preclude definite analysis of this. No malignancy is present. No granulomas are present.

Thank you for referring this case in consultation. Please keep me informed of any follow-up and call if you have questions. More precise morphological diagnosis will require additional tissue, and the need for more precise morphological diagnosis depends upon clinical circumstances. With best wishes,

Sincerely yours,

Eugene J. Mark, M.D. 

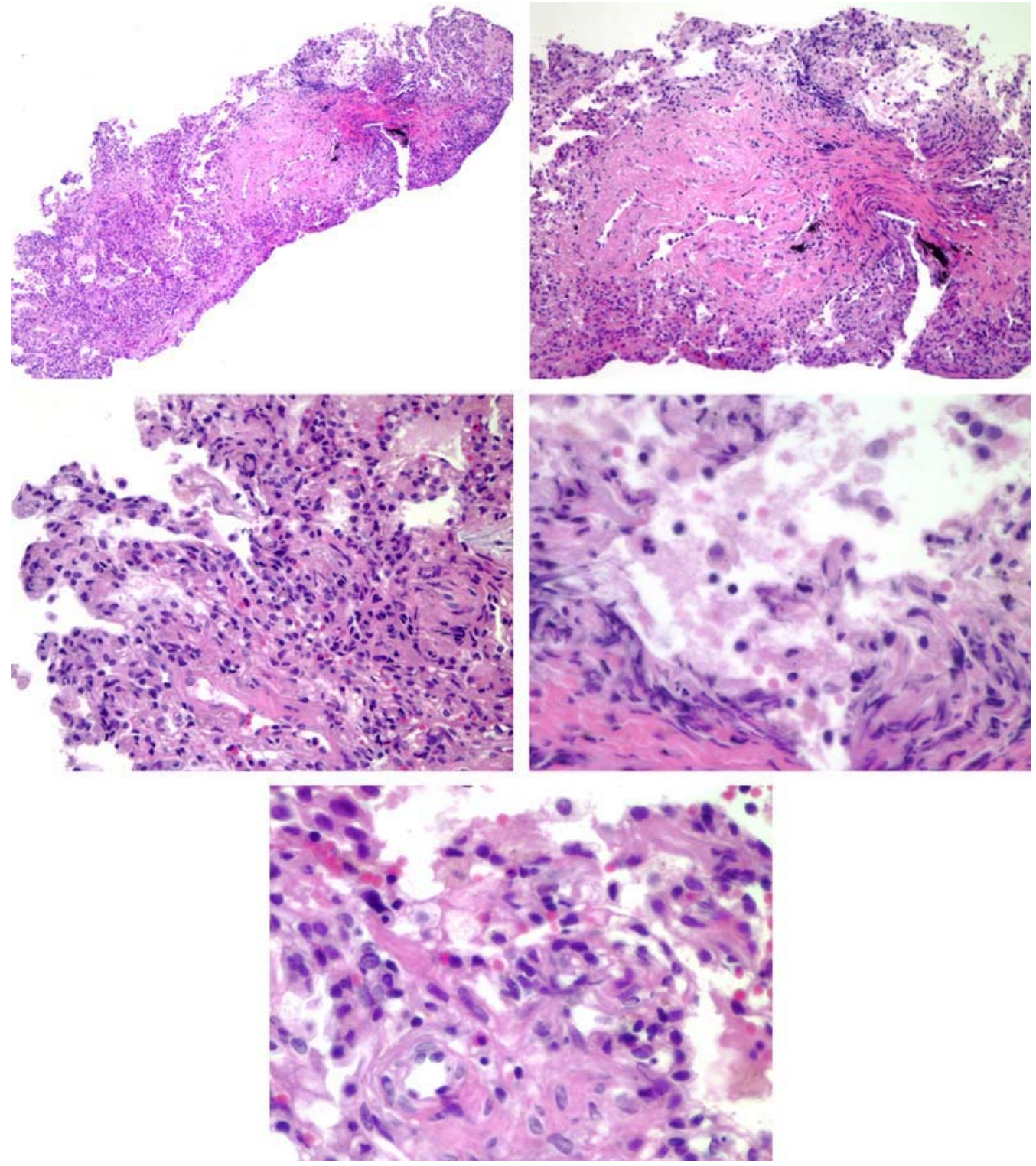

Case 6890 (Chapter 7 - Miscellaneous Pulmonary Disease) 


\section{Case 6962}

Diagnosis: Bronchus, bronchoscopic biopsy:

1. Compact granuloma, with focal slight central necrosis, etiology undetermined.

2. Eosinophilic infiltrate in lamina propria.

Two different processes are present, and I suspect that they represent two different diseases. The compact granulomas and their location in bronchial mucosa are consistent with sarcoidosis, but infection cannot be excluded despite the reportedly negative stains for organisms. The eosinophils in lamina propria most commonly would be seen in a patient with an asthmatic diathesis. CEP and other conditions of eosinophilic infiltrates cannot be excluded. Although granulomatous inflammation and eosinophils can both occur in bronchiolitis with hypersensitivity reaction and WG, I do not favor these interpretations.

Thank you for referring this case in consultation. Please keep me informed of any follow-up and call if you have questions. With best wishes,

Sincerely yours,

Eugene J. Mark, M.D. 

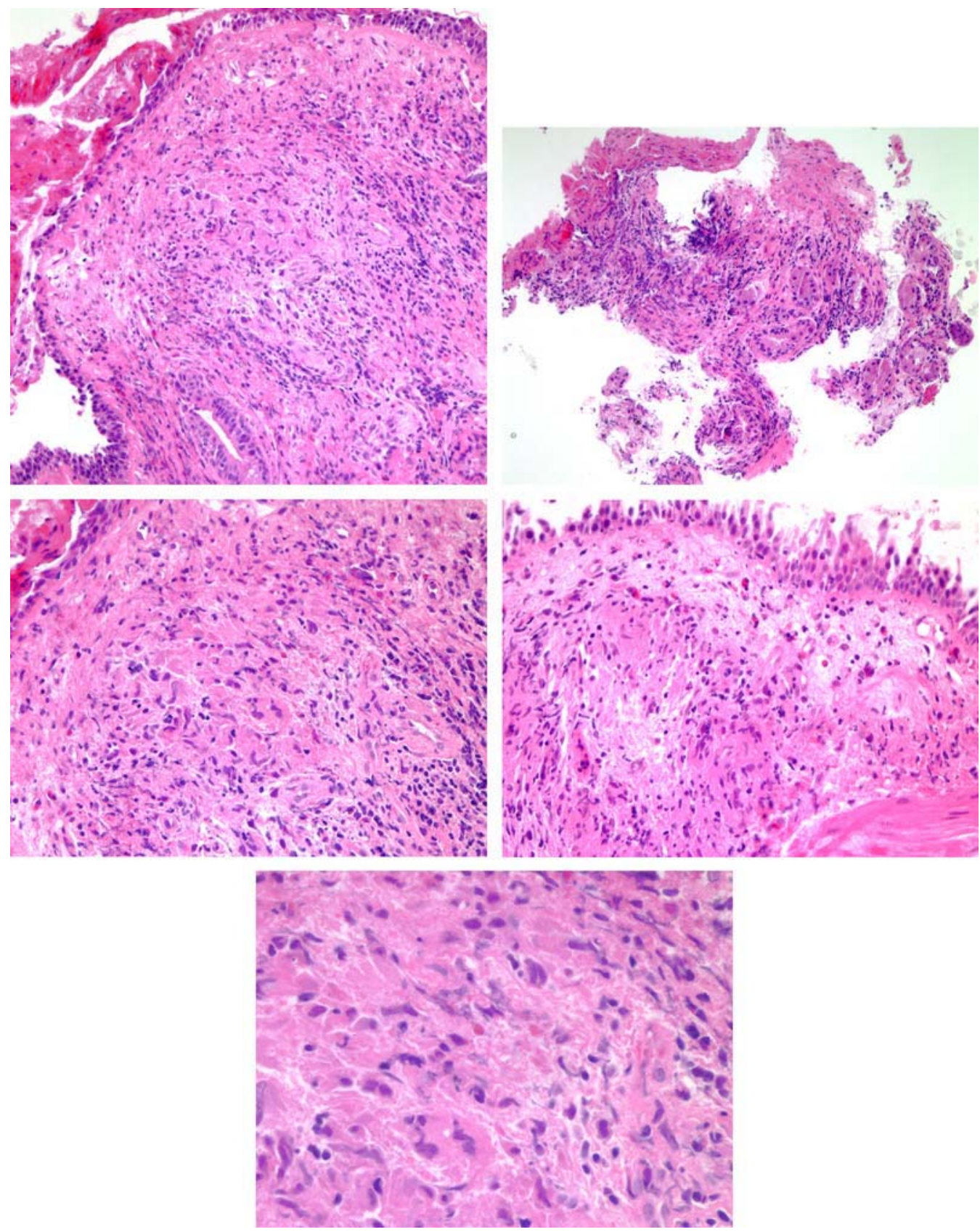

Case 6962 (Chapter 7 - Miscellaneous Pulmonary Disease) 


\section{Case 7150}

\section{Diagnosis: Lung, thoracoscopic biopsy: Hemosiderosis and capillary prolifera- tion, consistent with congestive vasculopathy.}

There is focal fibrous scarring, as you indicate, associated with moderate deposition of hemosiderin and pulmonary arterial hypertensive change (elastic stain). A few foci with proliferation of capillaries raise the possibility of pulmonary capillary hemangiomatosis as a cause of scarring and hemosiderin. In addition to increased numbers of capillaries in individual alveolar walls, there is intrusion of capillaries into walls of bronchioles and small blood vessels (PAS stain). Pulmonary capillary hemangiomatosis can be a condition which causes interstitial infiltrates on X-ray and pulmonary hypertension with cor pulmonale, it can be an incidental finding, or it can be a disease. To further substantiate the degree of capillary proliferation, I performed recut sections on a block of tissue in paraffin which you kindly provided and stained the recut sections with periodic-Schiff, elastic tissue, trichrome and Giemsa as well as prussian blue for iron. The periodic acidSchiff stain, particularly, shows the excess number of capillaries. I then reviewed the chest radiograph which you provided. Marked cardiac dilatation in conjunction with the clinical history indicates that the capillary proliferation as well as the hemosiderosis is probably secondary to congestive vasculopathy in this patient.

The permanent sections do not show any fungi or any necrosis or granulomatous reaction that might be associated with fungi. There are prominent fibers of elastica in the permanent sections, and it is sometimes very difficult on frozen sections to distinguish elastic fibers from hyphae. Degenerative elastica sometimes occurs in pulmonary vascular disease.

Thank you for referring this case in consultation. Please keep me informed of any follow-up and call if you have questions. Delay in reporting was due to the histochemical analysis as well as the review of the clinical and radiographic records and films. With best wishes,

Sincerely yours, Eugene J. Mark, M.D.

\section{Reference:}

Jing X, Yokoi T, Nakamura Y, et al. Pulmonary capillary hemangiomatosis. A unique feature of congestive vasculopathy associated with hypertrophic cardiomyopathy. Arch Pathol Lab Med 1998;122:94-96. 

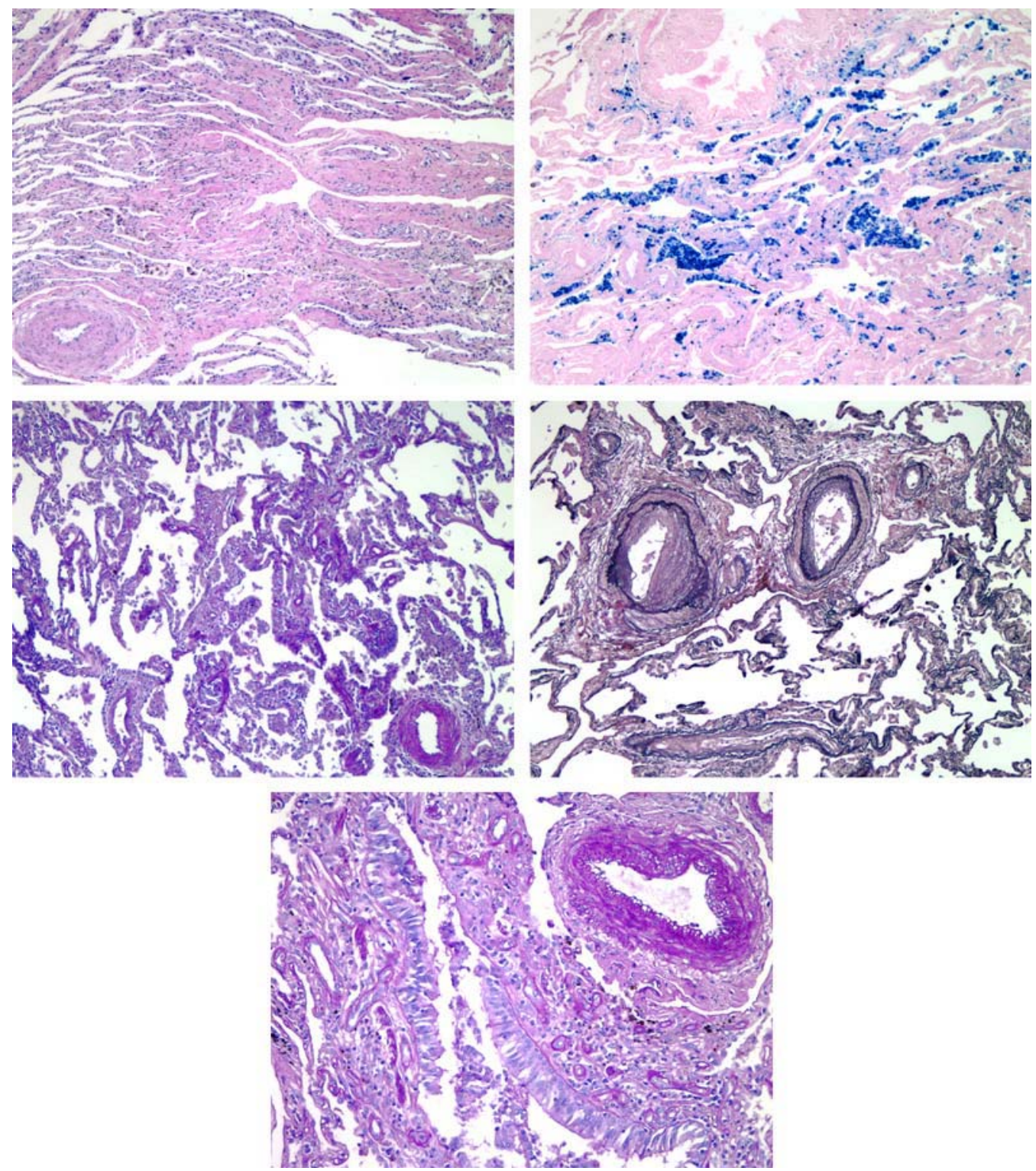

Case 7150 (Chapter 7 - Miscellaneous Pulmonary Disease) 


\section{Case 6541}

Diagnosis: Lung, open biopsy: Pulmonary hemorrhage and hemosiderosis, with probable capillaritis, and with DIP-like reaction.

Alveolar filling by histiocytes suggests DIP, but the abundant and coarse hemosiderin is not typical for that condition. Absence of eosinophils amidst the histiocytes is additional evidence against DIP. Therefore, I believe the better clinicopathological diagnosis is a pulmonary hemorrhage syndrome with DIP-like reaction. There is fresh blood in the lung. Although some may be operative, blood in terminal bronchioles suggests active flow and consequently real hemorrhage. There are collections of neutrophils with fibrin in a few alveoli and in interstitium of the type sufficient for me to suspect that there are now and have been episodes of capillaritis. I cannot make that diagnosis unequivocally because the neutrophils are spotty, not particularly associated with the fresh hemorrhage, and not associated with detectable fibrinoid necrosis of blood vessels or with fibrin thrombosis of capillaries. If one cannot prove capillaritis, the remaining diagnosis in this case would be IPH, but I believe the evidence for capillaritis is strong enough so that I suspect the bleeding is due to lupus erythematosis, WG, or one of the other less frequent causes of capillaritis. Goodpasture's syndrome usually does not produce capillaritis in the lung.

Thank you for referring this case in consultation. Please keep me informed of any follow-up and call if you have questions. With best wishes,

Sincerely yours,

Eugene J. Mark, M.D. 

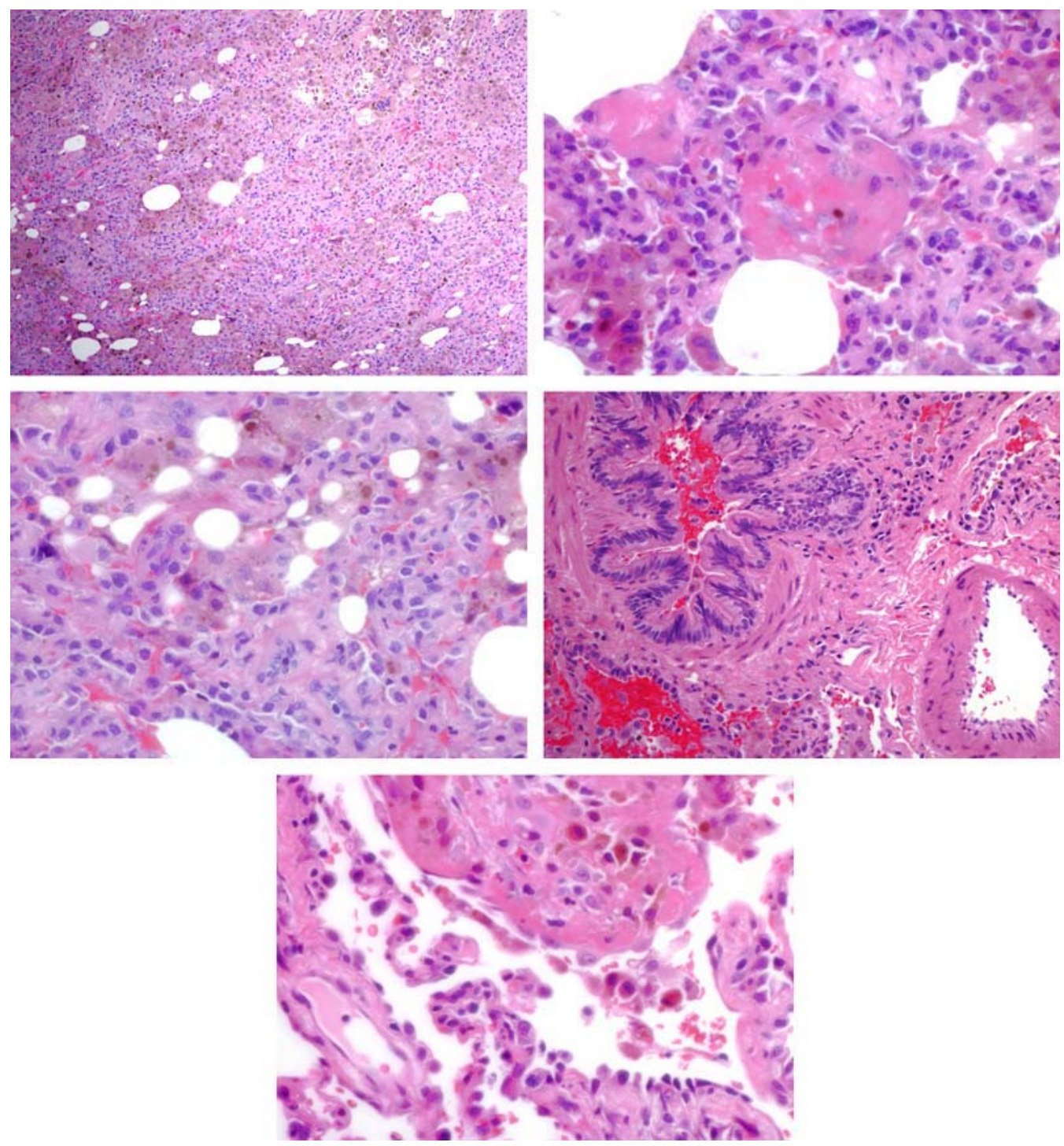

Case 6541 (Chapter 7 - Miscellaneous Pulmonary Disease) 


\section{Case 6911}

\section{Diagnosis: Lung, open biopsy:}

1. Hemosiderosis, cause uncertain, ? IPH.

2. Linear sclerosis, involving septa and pleura, significance uncertain, ? early dendriform ossification, ? veno-occlusive disease, ? other.

We can diagnose hemosiderosis (iron stain) by virtue of the old and focal recent hemorrhage. No capillaritis is present. Pleural adhesions are present. IPH is possible, but I use this diagnosis only as a last resort and diagnosis of exclusion. WG and Goodpasture's syndrome could be assessed by serologic study because some cases of so-called IPH have ultimately proved to be one of these two diseases. Mitral lung would enter the differential diagnosis, but I understand that mitral valvular disease has already been excluded.

An enigmatic abnormality is the dense sclerosis involving lobular septa (trichrome stain) and the adventitia of small intralobular veins (elastic stain), as you indicate. This raises the possibility of veno-occlusive disease, but usually there is more inflammation and hemosiderin around the veins in that condition as well as luminal occlusion by fibrosis, which is not present either on your slides or in the elastic and trichrome stains which we performed on the block which you kindly provided. Secondary arterial hypertension often develops in patients with veno-occlusive disease, but in this case there is only mild medial thickening of some arteries. Focal ossification is present, and the ossification seems to develop in some of the fibrotic foci, leading to the possibility that this is a forme fruste of dendriform ossification of the lung. Dendriform ossification usually has been reported as an incidental finding. There have been associations with tuberculosis, mitral lung, heart failure, and pneumoconiosis. I am not aware of an association with pulmonary hemorrhage other than mitral valve disease.

Thank you for referring this case in consultation. Please keep me informed of any follow-up. This is an elaboration of my telephone call. With best wishes,

Sincerely yours,

Eugene J. Mark, M.D.

References:

Chow LTC, Shum BSF, Chow WH, Tso CB. Diffuse pulmonary ossification - a rare complication of tuberculosis. Histopathology 1992;20:435-437.

Fried ED, Godwin TA. Extensive diffuse pulmonary ossification. Chest 1992;102:1614-1615.

Jones RW, Roggli VL. Dendriform pulmonary ossification. Report of two cases with unique findings. Am J Clin Pathol 1989;91:398-402. 

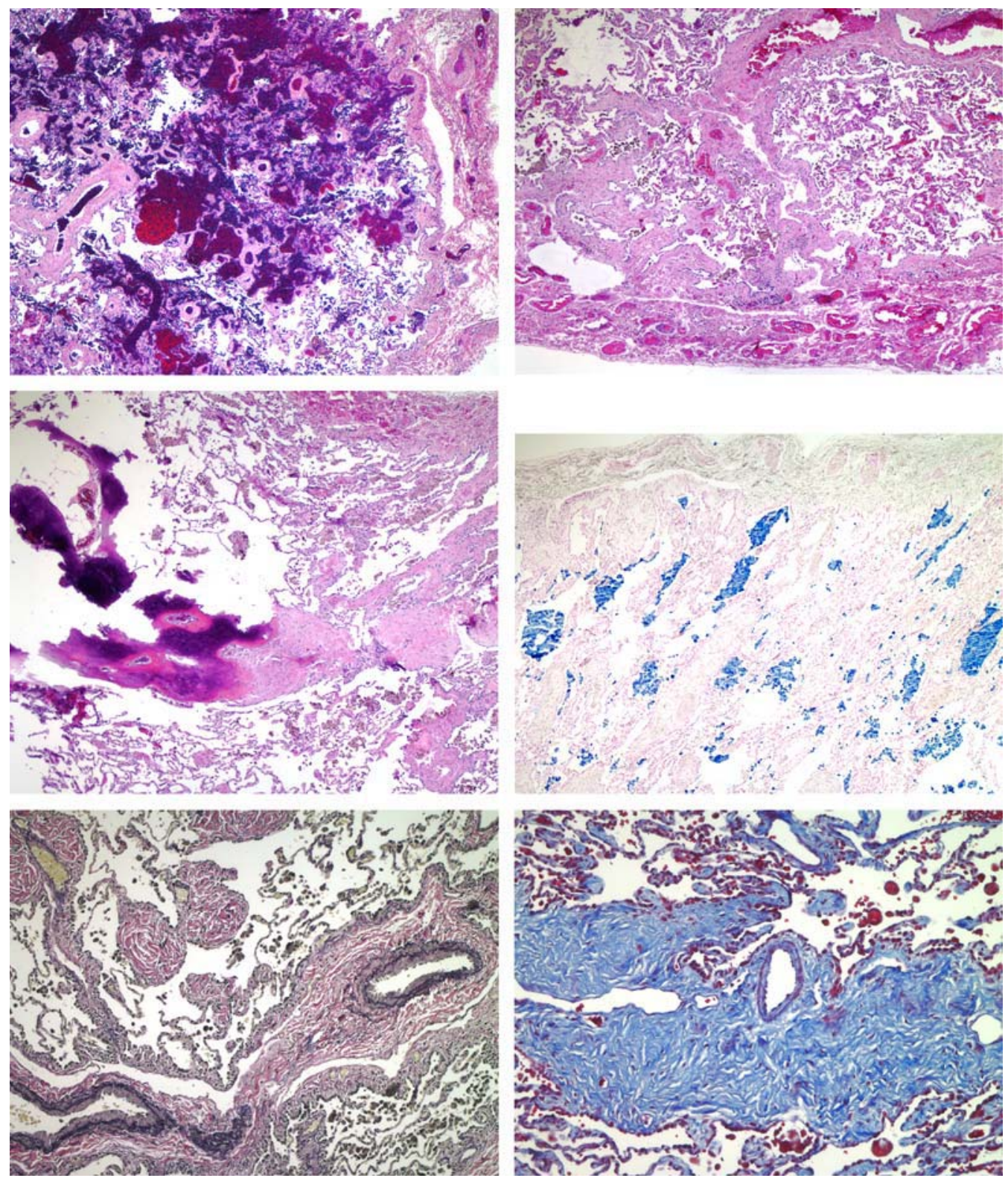

Case 6911 (Chapter 7 - Miscellaneous Pulmonary Disease) 


\section{Case 4432}

\section{Patient: 27-yr-old male}

Diagnosis: Lung, resection of bullae: Subpleural bullae and focal destructive arterial lesions with hemorrhage, ? elastic tissue disease (? pseudoxanthoma elasticum, ? Ehlers-Danlos, ? other).

This patient had an unusual disease which I cannot categorize from the available information. However, I am fairly certain that this is some form of elastic tissue disease. The subpleural bullae can be seen in pseudoxanthoma elasticum, Ehlers-Danlos disease, and Marfan syndrome. Very little elastica stains on your elastic tissue stains, although wavy refractile elastic-like fibers are present in arteries and pleura. I am not sure whether this stain is technically in error or whether the apparent elastic tissue is chemically abnormal. However, degenerate clumped elastic fibers are visible due to their iron encrustation on the iron stain. Abnormal elastic fibers are present on one side of an artery, and elastic fibers are absent on the opposite side of the artery. The focal areas of hemorrhage with punctate acute necrosis, some regions of organizing hemorrhage a few days old, and extensive hemosiderin (iron stain) and fibrosis indicative of hemorrhage weeks or months old suggest that the bleeding has been due to repetitive arterial destruction and rupture rather than nonspecific hemorrhage from a ruptured bulla. These changes have been described previously in pseudoxanthoma elasticum and Ehlers-Danlos syndrome. Various other clinical findings might substantiate or refute these diagnoses. Elastic tissue diseases have many subcategories. Therefore, I do not know whether this patient fits into any clearly described entity. You might consider working this case up further, because it might be an initial manifestation of such a disease and possibly the subject of a case report.

We are currently studying elastic tissue in patients with Marfan syndrome. Although the clinical appearance of the patient suggests Marfan syndrome and these patients have repeated pneumothorax, we have not seen marked abnormalities in elastica nor significant pulmonary hemorrhage in patients with Marfan syndrome. I do not favor a diagnosis of Marfan syndrome.

Thank you for referring this case in consultation. With best wishes,

Sincerely yours,

Eugene J. Mark, M.D.

\section{References:}

Jackson A, Loh C-L. Pulmonary calcification and elastic tissue damage in pseudoxanthoma elasticum. Histopathology 1980;4:607-611.

Huang S-N, Steele HD, Kuma G, Parker JO. Ultrastructural changes of elastic fibers in pseudoxanthoma elasticum. A study of histogenesis. Arch Pathol 1967;83:108-113.

Corrin B, Simpson CGB, Fisher C. Fibrous pseudotumours and cyst formation in the lungs in Ehlers-Danlos syndrome. Histopathology 1990;17:478-479.

McFarland W, Fuller DE. Mortality in Ehlers-Danlos syndrome due to spontaneous rupture of large arteries. N Engl J Med 1964;271:1309-310.

Haraguchi S, Fukuda Y. Histogenesis of abnormal elastic fibers in blebs and bullae of patients with spontaneous pneumothorax: ultrastructural and immunohistochemical studies. Acta Pathologica Japonica 1993;43:709-722.

Wood JR, Bellamy D, Child AH, Citron KM. Pulmonary disease in patients with Marfan syndrome. Thorax 1984;39:780-784. 

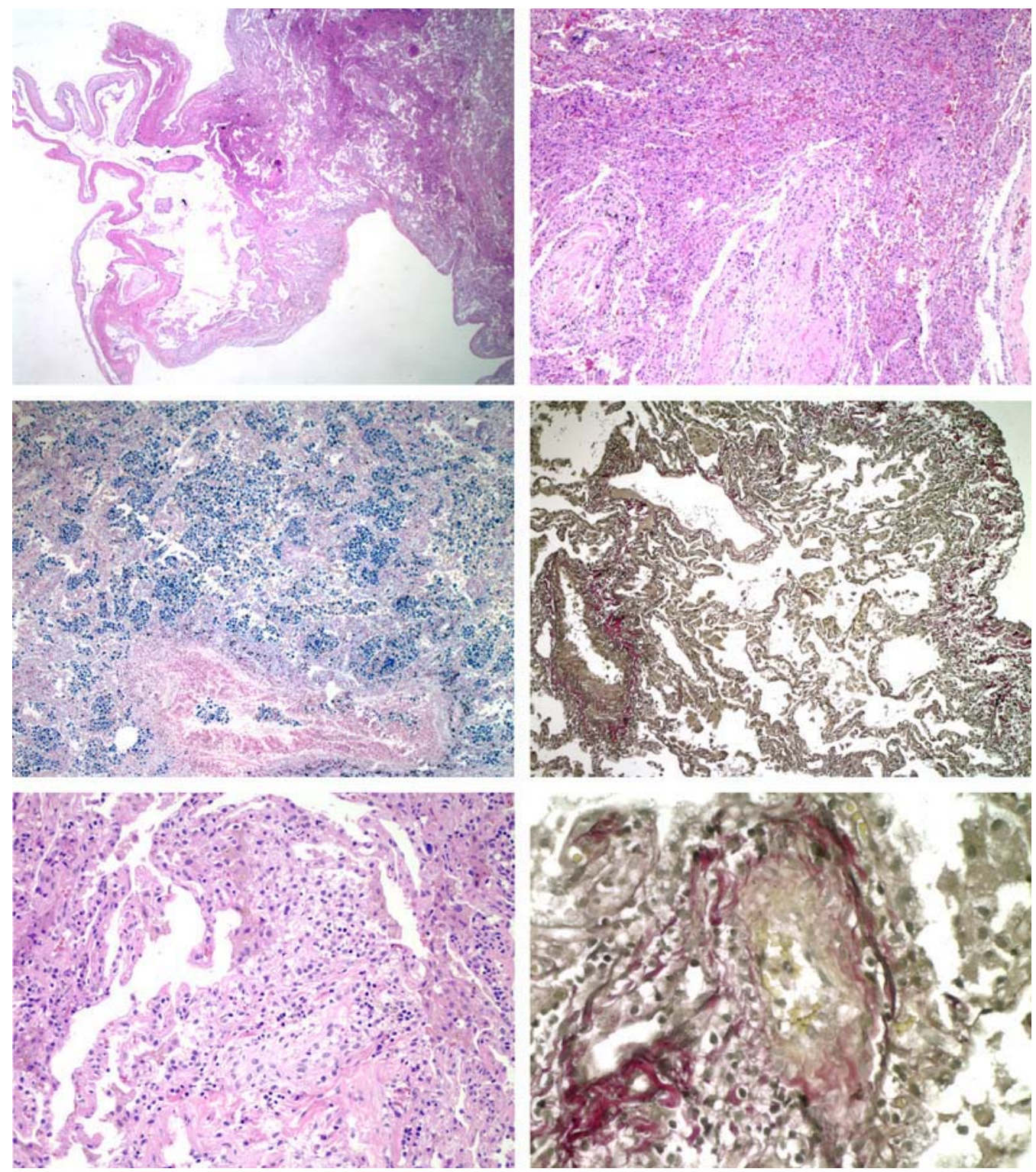

Case 4432 (Chapter 7 - Miscellaneous Pulmonary Disease) 


\section{Case 6549}

Diagnosis: Lung, open biopsy: Pulmonary hemorrhage and hemosiderosis, ? collagen-vascular disease, ? other.

Extensive hemorrhage and hemosiderosis are associated with an interstitial thickening due to lymphocytes and probably fibrosis as well. The most common causes of this condition in our experience are WG, Goodpasture's syndrome, and lupus erythematosis. The slightly elevated ANA raises the possibility that the patient may have a variety of lupus erythematosis. WG could be further investigated by serum anti-neutrophilic cytoplasmic antibody (ANCA). Capillaritis would explain the hemorrhage, but I detect no capillaritis in this patient. Patients may have episodes of capillaritis without our ability to morphologically document it between episodes of active bleeding. I suspect that is the case in this patient. I detect no arteritis or phlebitis, but there is a recent thrombus with peripheral organization in one slide next to a terminal bronchiole. Acute and chronic hemorrhage and interstitial pneumonitis have been described with regularity at autopsy in patients who have used cocaine, and I cannot exclude this possibility. No birefringent particles are present within vessels.

Thank you referring this case in consultation. Please keep me informed of any followup. With best wishes,

Sincerely yours,

Eugene J. Mark, M.D.

Reference:

Bailey ME, Fraire AE, Greenburg SD, Barnard J, Cagle PT. Pulmonary histopathology in cocaine abusers. Hum Pathol 1994;25:203-207. 

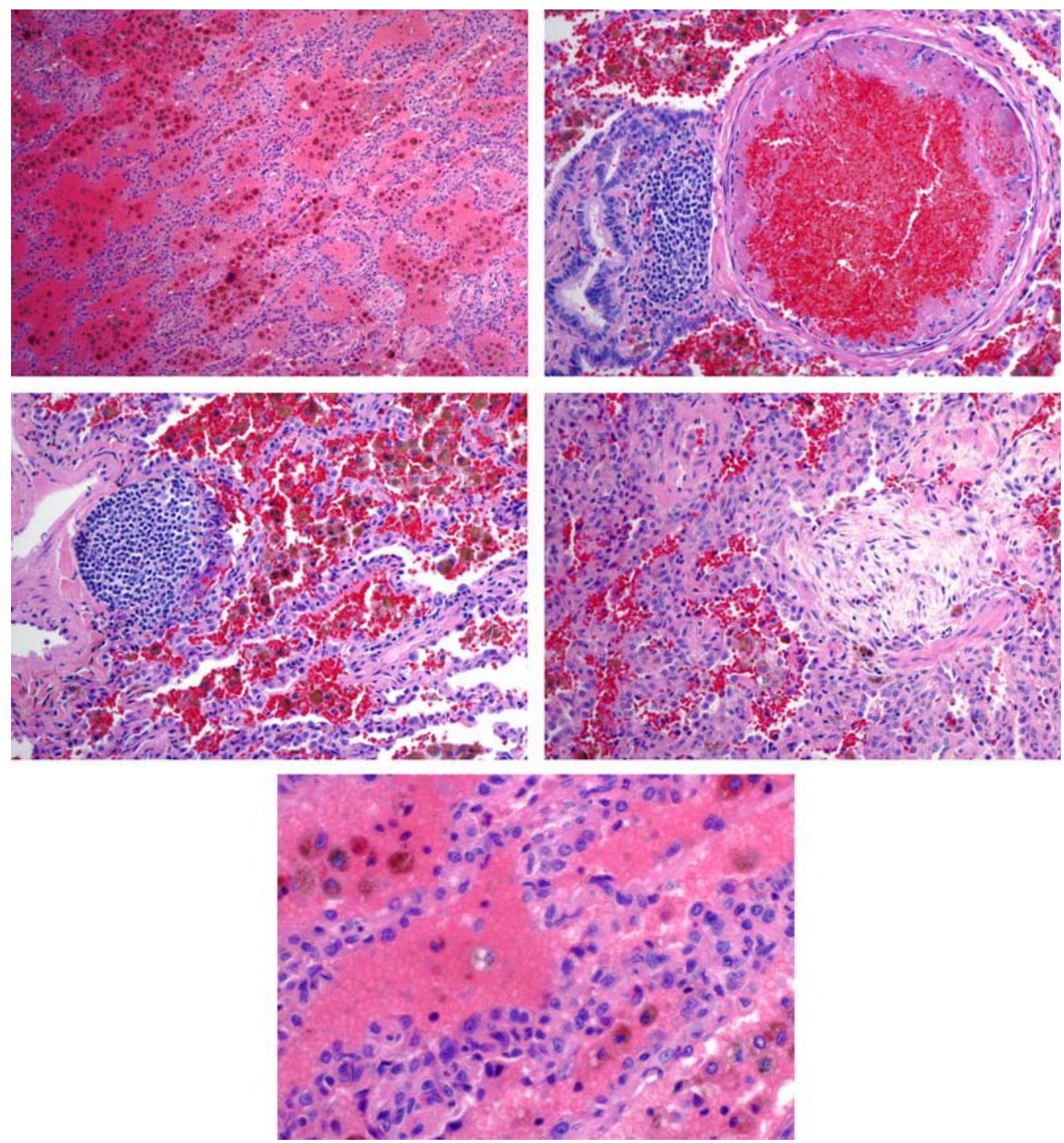

Case 6549 (Chapter 7 - Miscellaneous Pulmonary Disease) 


\section{Case 6867}

\section{Diagnosis: Lung, open biopsy:}

\section{Adenocarcinoma, bronhioloalveolar subtype.}

\section{Asbestosis.}

Histopathologically, the open biopsy consists of lung which contains tumor. The largest piece of tissue is approx $5 \mathrm{~mm}$ in greatest diameter. The lung contains an adenocarcinoma. The malignant cells spread along walls of alveoli in a lepidic manner. Nuclei are hyperchromatic and oval with relative opacity of some of the nuclei and central clearing in other nuclei. Nucleoli are relatively inconspicuous. The malignant cells are cuboidal or columnar. Some of the malignant cells have snouts at the apex of the cytoplasm, typical of Clara cells. The alveolar walls have fibrous thickening. A slight lymphocytic infiltrate is present in the interstitium. In one piece the carcinoma cells form regular glands imbedded in more abundant fibrous stroma with elastotic scarring. The pathological findings indicate an adenocarcinoma of bronchioloalveolar subtype.

Histopathologically, the lung contains a moderate amount of carbon and many asbestos bodies. The asbestos bodies are long, brown, beaded, and have thin translucent cores. The asbestos bodies lie singly or in groups of two or three together. The asbestos bodies lie in interstitial fibrosis amidst tumor and in interstitial fibrosis away from tumor.

I quantify the asbestos bodies by optical microscopy. The asbestos bodies are present at a concentration of approx 10 per square centimeter of lung and tumor tissue. The combination of the interstitial fibrosis and the asbestos bodies constitutes parenchymal asbestosis.

From a block of the tumor embedded in paraffin, I have obtained recut slides for histochemical studies. Trichrome stain delineates interstitial fibrosis amidst carcinoma and interstitial fibrosis away from carcinoma. Mucicarmine stain shows intracellular mucin in a small number of carcinoma cells. Prussian blue stain colors the asbestos bodies blue.

From the same block of the tumor embedded in paraffin, I have obtained recut slides for immunochemical studies. One slide has been stained for prostate specific antigen by the immunoperoxidase technique. A second slide has been stained for prostatic acid phosphatase by the immunoperoxidase technique. The malignant cells do not stain for prostatic acid phosphatase nor for prostate specific antigen. The histochemical and immunochemical results are consistent with an adenocarcinoma of bronchiolo-alveolar subtype that has arisen in the lung.

Cigarette smoke and asbestos each can cause carcinoma of the lung, including adenocarcinoma. Together, cigarette smoke and asbestos act in a synergistic manner to cause carcinoma of the lung. All of the types of asbestos can cause carcinoma of the lung. All of the exposures to asbestos which occur prior to the development of the carcinoma contribute to its pathogensesis.

I conclude that the patient developed an adenocarcinoma of bronchioloalveolar subtype that arose in the lung. I conclude that the patient inhaled asbestos. I conclude that the adeoncaricnoma of the lung caused death.

Sincerely yours,

Eugene J. Mark, M.D. 

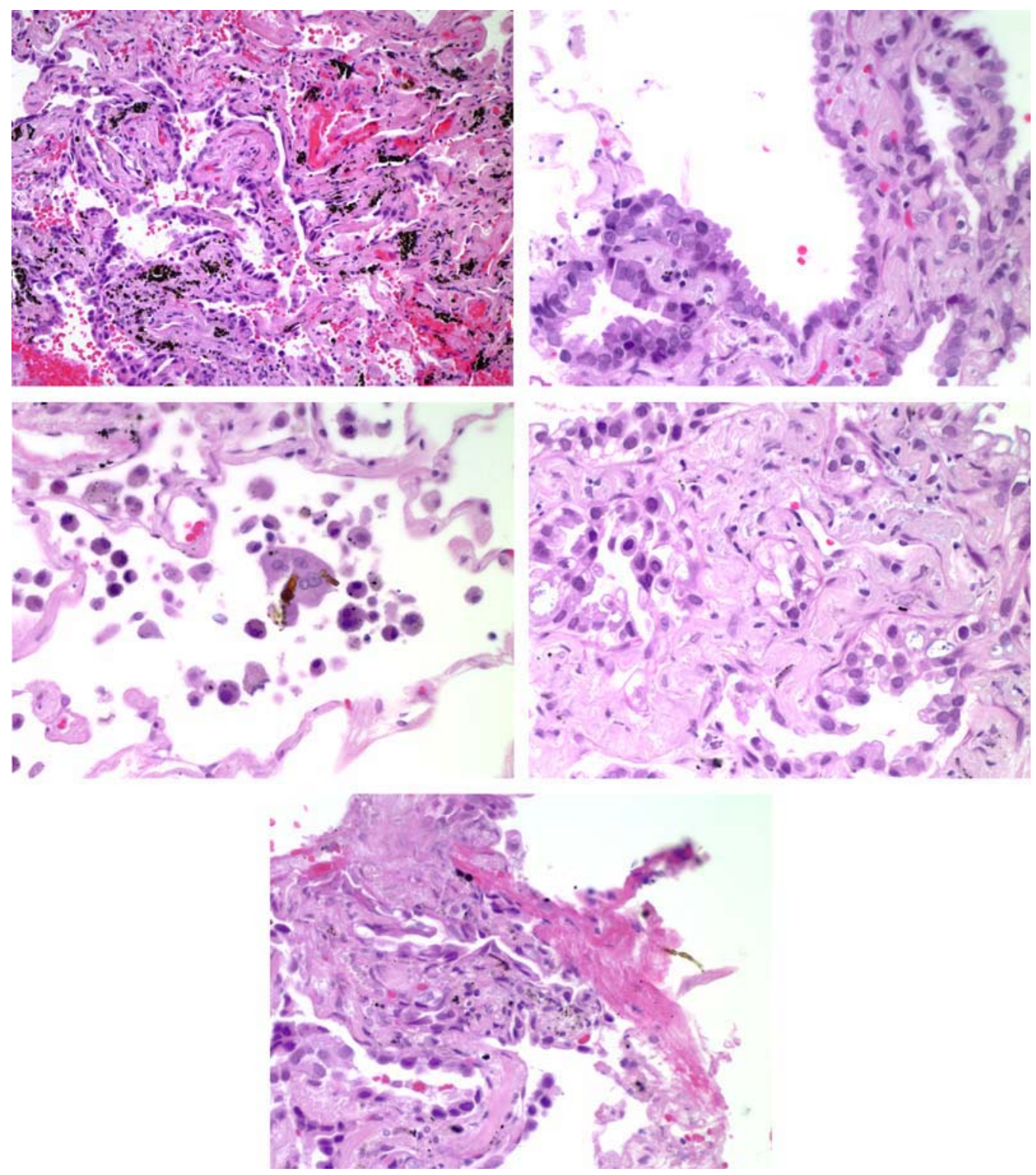

Case 6867 (Chapter 7 - Miscellaneous Pulmonary Disease) 


\section{Case 6917}

Diagnosis: Lung, wedge biopsy:

1. Silicatosis, nodular and linear, extensive.

2. Organizing fibrinous pneumonia.

I have examined microscopically approx 15 glass slides, the most salient of which are histological preparations of a wedge biopsy of the lung. The specimen was obtained at surgery in 1995. The slides of the wedge biopsy have been stained with hematoxylin and eosin.

Histopathologically, a diffuse histiocytic infiltrate arrranged in ill-defined nodules and linearly along lymphangitic pathways around bronchovascular bundles and in septa and in pleura. The histiocytic inflammation is, in large part, granulomatous. Extensive carbon pigment, as well as crystals of silicate, are present in the granulomatous inflammation. The silicate is seen with routine microscopy and with polarization microscopy. One region has central focal necrosis within fibrous scar of the type seen in silicosis. No asbestos bodies are present.

Histopathologicaly, the organizing fibrinous pneumonia is a separate and more recent process. A few hyaline membranes are present. The cause of the fibrinous pneumonia is uncertain based on the pathology materials alone.

Sincerely yours,

Eugene J. Mark, M.D. 

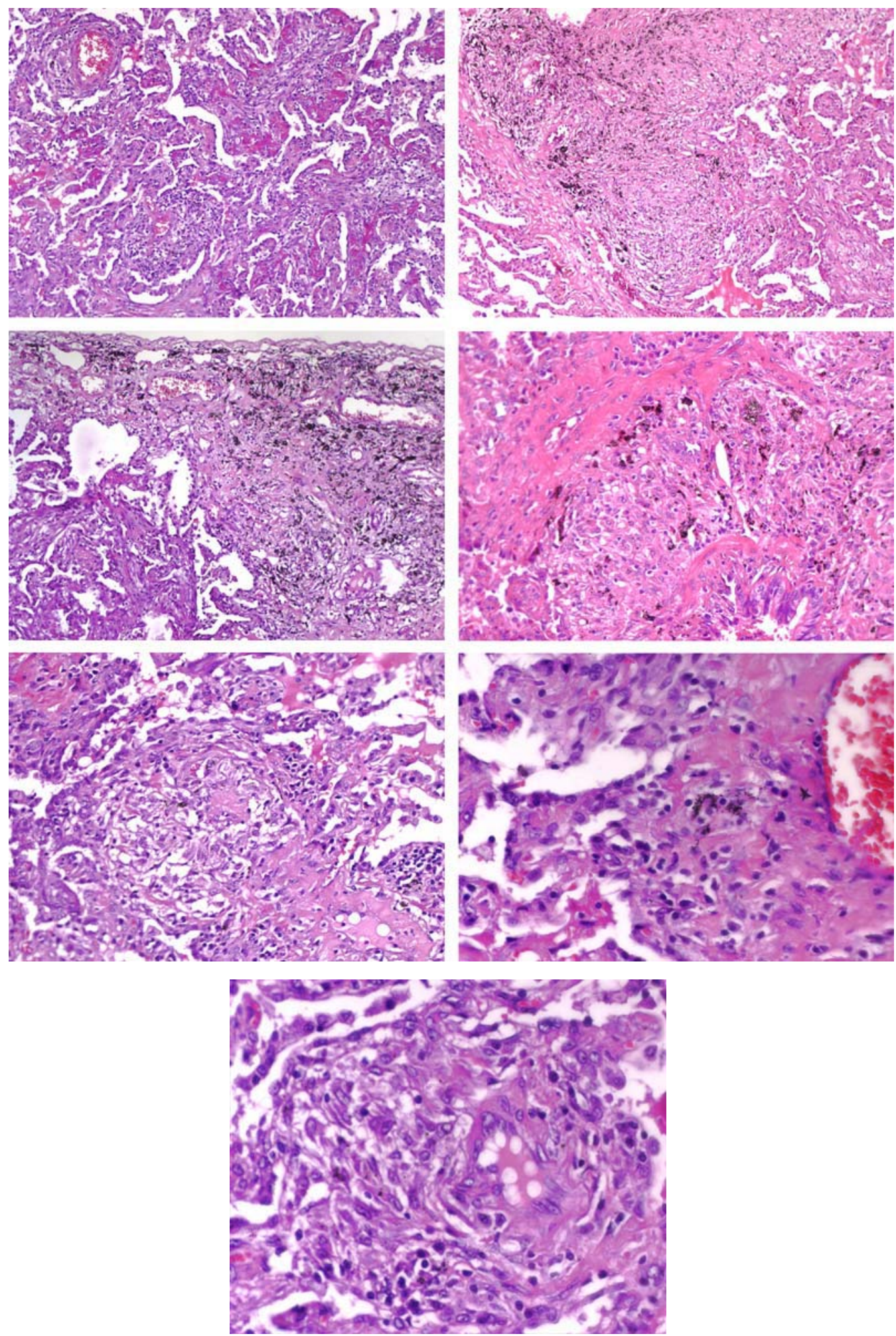

Case 6917 (Chapter 7 - Miscellaneous Pulmonary Disease) 


\section{Case 6834}

Diagnosis: Lung, open biopsy: Necrobiotic nodule, cause undetermined, ? rheumatoid nodule.

The necrobiosis with preserved elastica on special stains and palisading histiocytes (PAS stain) in at least a portion of the perimeter of the nodule makes me consider rheumatoid nodule as the best classical diagnosis for this lesion. Our special stains for organisms are negative. I cannot discount the reported history of drug abuse, which might predispose a person to embolic disease, but I could find no report in the literature of necrobiotic nodules associated with illicit drug abuse, nor have I seen such a case. I would expect a septic embolus to be more purulent.

On your section and on our special stains is a marked intimal proliferation of vessels (trichrome stain) in and near the necrobiotic nodule. I believe this intimal sclerosis is a secondary phenomenon and do not favor a primary vascular disease, although I cannot exclude that possibility. I considered WG or other vasculitis, but I do not favor this interpretation. Occasionally rheumatoid nodules may be the initial sign in patients who subsequently develop rheumatoid disease.

Thank you very much for sharing this case with us. All of the fellows on the service in pulmonary pathology enjoyed reviewing the case. I hope this finds you and your family well and prosperous. With best wishes for the new year,

Sincerely yours,

Eugene J. Mark, M.D. 

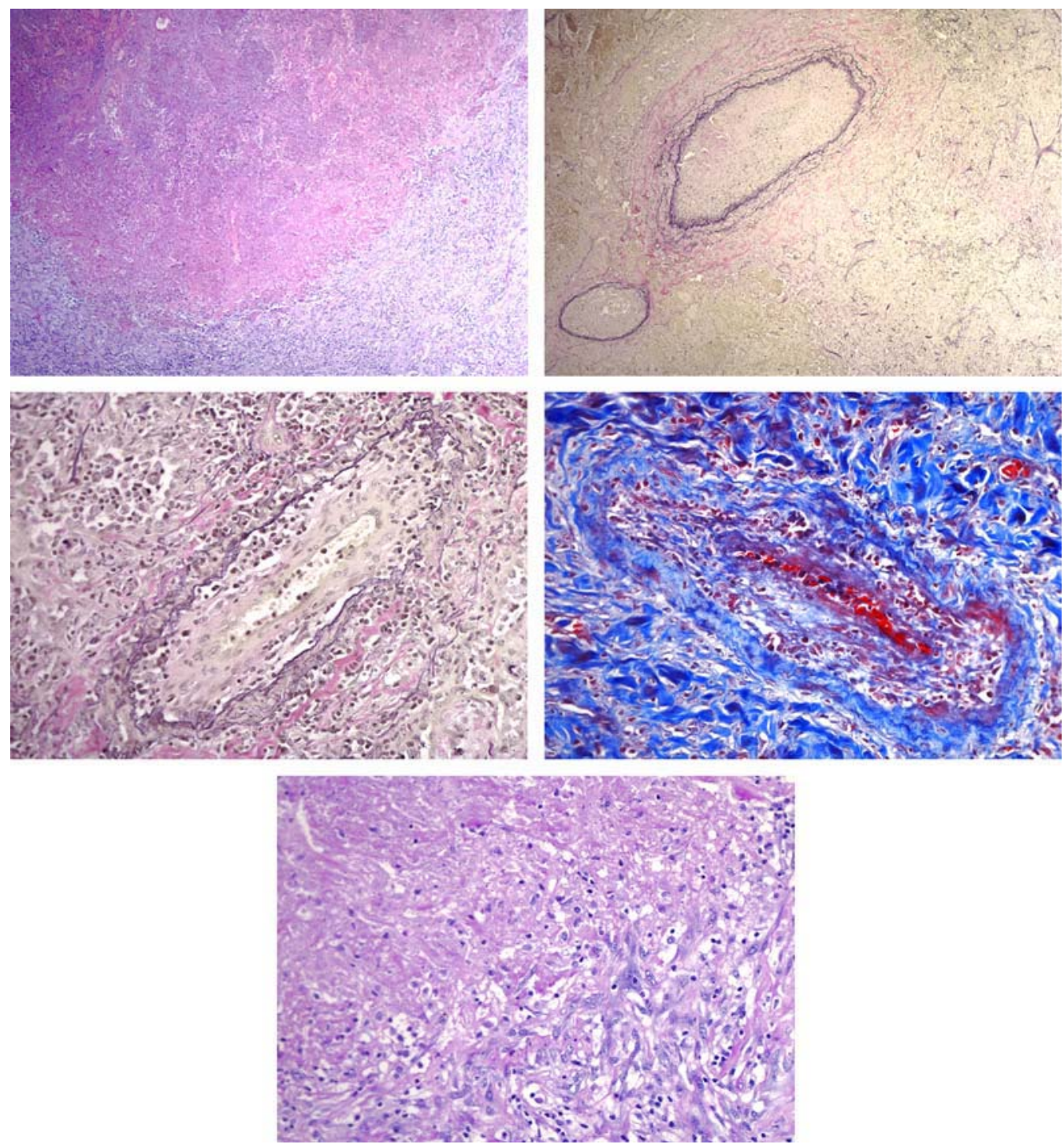

Case 6834 (Chapter 7 - Miscellaneous Pulmonary Disease) 


\section{Case 6874}

\section{Diagnosis: Lung, open biopsies:}

1. Calcified intra-arterial nodule (wedge $A)$.

2. Intraparenchymal lymph node (wedge B).

In wedge $\mathrm{A}$ is an unusual calcified nodule in the media of a pulmonary artery with eccentric protrusion into the lumen. The change could represent a calcified thromboembolus or a calcified intramural hematoma. In either case, the process is months or years old, without activity. The lumen of the vessel seems to remain patent. The lesion on the slide is about $3 \mathrm{~mm}$ in greatest diameter, so I am uncertain whether or not this accounts for a radiographic finding, but I could conceive of it as having been palpable at surgery or visualized on a computerized tomogram because it is calcified. In wedge B is a small intrapulmonary lymph node measuring about $2 \mathrm{~mm}$ in diameter. Again, I do not know whether this is the cause of a radiographic nodule, but in my experience intraparenchymal lymph nodes are one of the more common causes of "disappearing tumors of the lung." It is possible that our section has not passed through the main diameter of the nodule and that it could have been larger.

Apart from these two lesions is multifocal blood in the lung. I suspect that this is operative for the following reasons: 1) absence of hemosiderin suggests that it has not been present for more than $48 \mathrm{~h} ; 2$ ) the alveoli are compressed rather than expanded by blood, whereas bleeding into alveoli tends to expand them; 3 ) no capillaritis or vasculitis is present; 4) the lung in some areas of blood is atelectatic suggesting mechanical effect. The lung otherwise has pigment-laden histiocytes around bronchioles, a few alveolar histiocytes, and pleural adhesions.

In the differential diagnosis of disappearing tumors in the lung, I also considered in this case shrinking pleuritis with rounded atelectasis and arteriovenous malformation. However there is no evidence for these conditions on the slides, and the wedge resections have been thoroughly examined by your technique.

Thank you for referring this case in consultation. Please keep me informed of any follow-up and call if you have questions. All of your slides are returned under separate cover. With best wishes,

Sincerely yours,

Eugene J. Mark, M.D. 

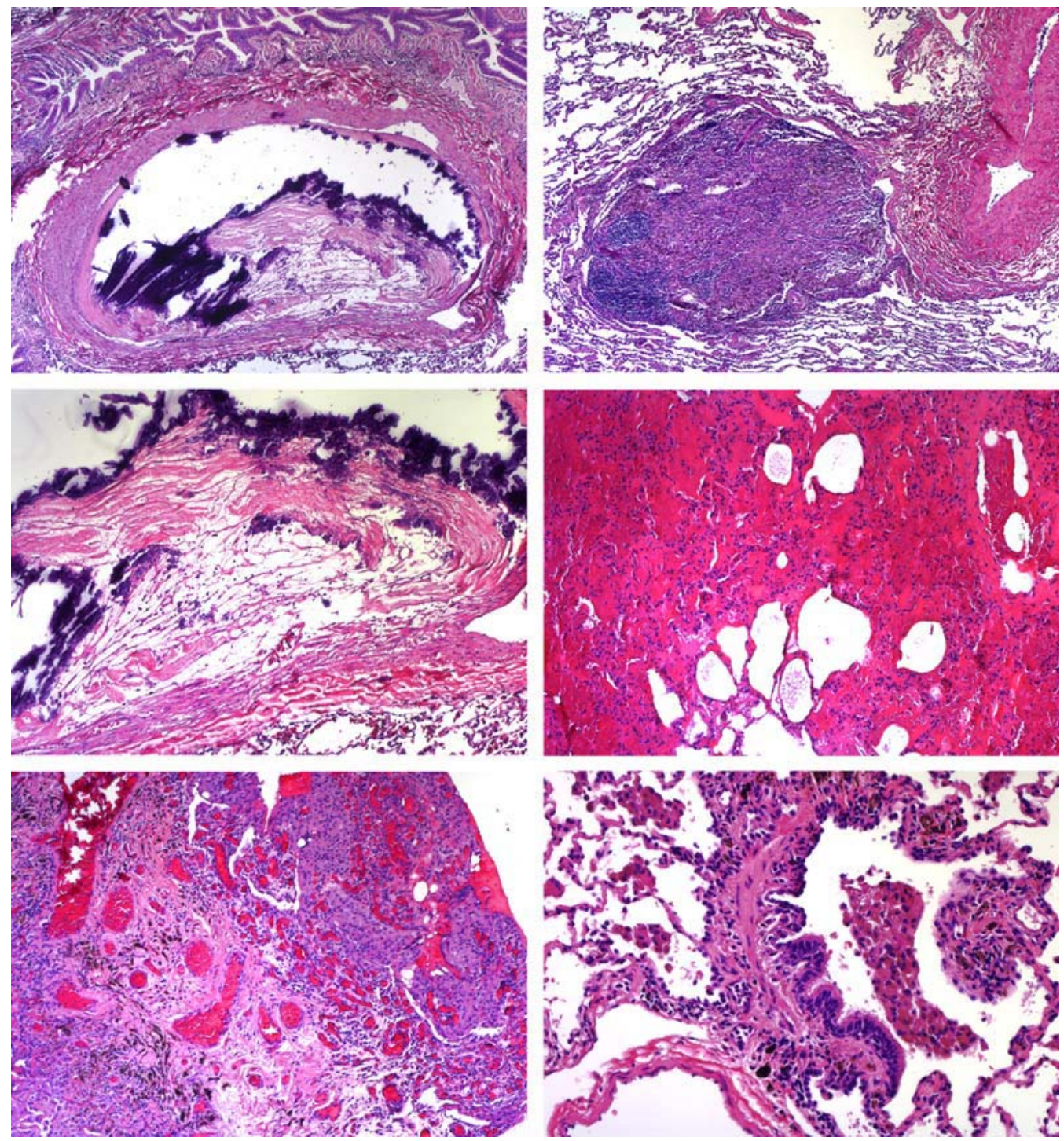

Case 6874 (Chapter 7 - Miscellaneous Pulmonary Disease) 


\section{Case 6926}

Patient: 69-yr-old male, who had a spontaneous gastric perforation following arthroscopic knee surgery. He was on ventilator support for 6-8 wk. His ARDS cleared, now leaving atelectasis and a left pleural effusion. A CT scan showed no mass.

Diagnosis: Bronchus, bronchoscopic biopsy and washings: Focal ulceration, with atypical squamous metaplasia, including highly atypical reactive epithelial cells.

The cytological preparations show squamous epithelial cells and clumps of atypical epithelial cells with enlarged nuclei. Multiple and enlarged nucleoli in some of the nuclei make one seriously consider carcinoma. However, the highly atypical cells are few in number when considering the totality of the case, and the nuclei preserve a relative regularity in size. The biopsy shows a focal ulceration which has been present for many days because there is fibrosis and capillary proliferation beneath it. Adjacent to this ulceration is squamous metaplasia with regeneration and highly atypical nuclei. The cytological features in the bronchial epithelium resemble those in the cytological preparation. Although I do not know that this particular site is the source of the highly atypical cells seen on the cytological preparations, the atypical cells in the washings are consistent with reactive epithelial cells such as might occur with ulceration. In any case, I do not believe the cytological preparations are diagnostic of malignancy.

Thank you for referring this case in consultation. Please keep me informed of any follow-up.

Sincerely yours,

Eugene J. Mark, M.D. 

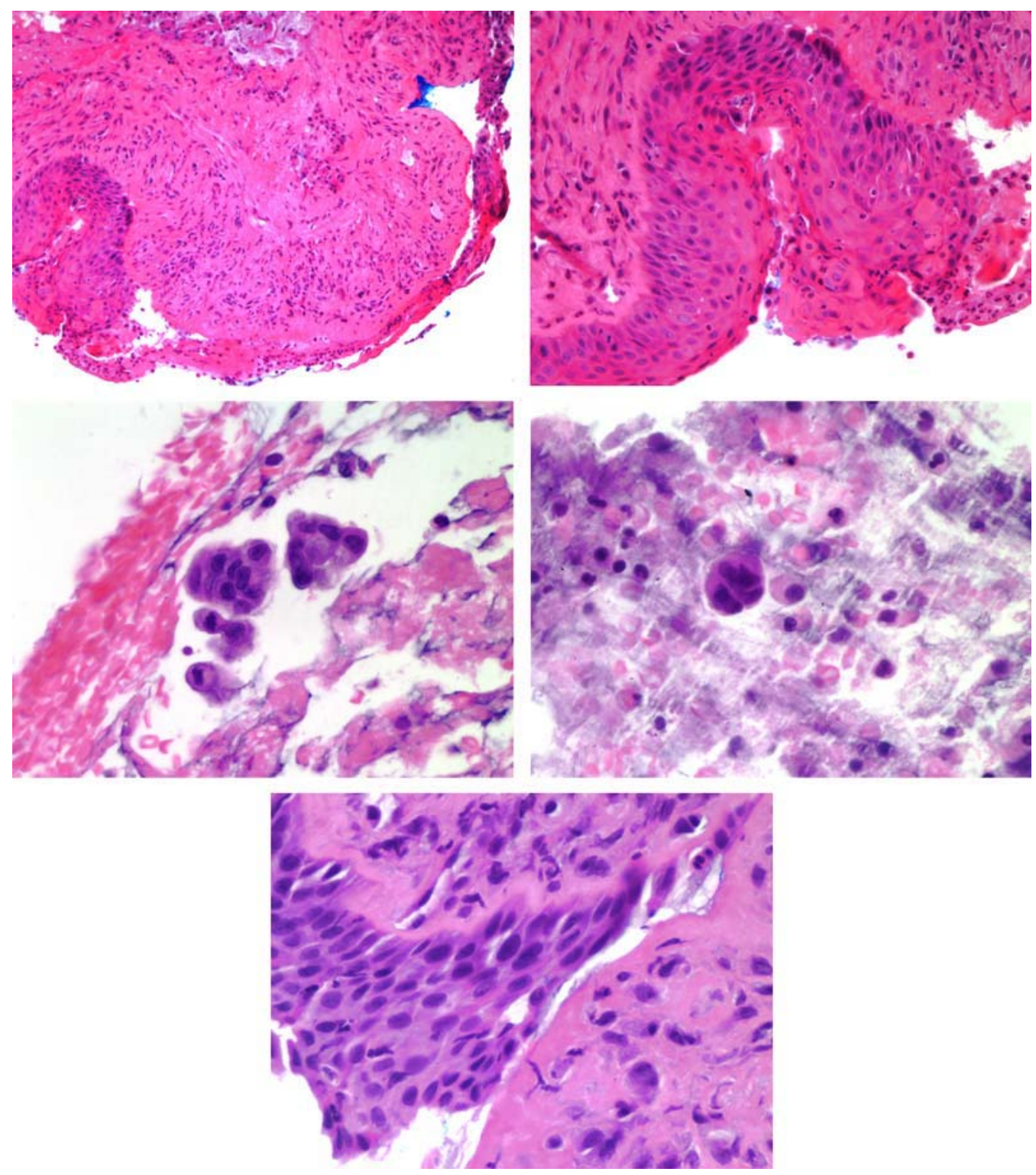

Case 6926 (Chapter 7 - Miscellaneous Pulmonary Disease) 


\section{Case 6603}

Diagnosis: Lung, open biopsy:

1. Compact granulomas, few, scattered.

2. Mucus plugs and pigmented histiocytes in alveolar ducts, ? respiratory bronchiolitis (RB).

3. Emphysema, subpleural.

4. Hemosiderin.

The most specific findings are the scattered interstitial granulomas, as you indicate. These raise a possibility of hypersensitivity reaction, but the bronchiolitis commonly seen with hypersensitivity reaction is not present. There is emphysema with free-floating fragments of alveolar walls near the pleura, mucus plugging of terminal bronchioles, and pigment-laden histiocytes in alveolar ducts. These are all sequelae of the smoking of cigarettes. Finally, there is the presence of hemosiderin indicative of prior focal hemorrhage, the cause of which is uncertain.

I cannot determine which of these processes is the most important disease clinically. I cannot exclude sarcoidosis, but I doubt it. RB can produce small nodules, but the degree of filling of alveolar ducts by pigmented histiocytes is not sufficient for a morphologic diagnosis of RB. I cannot be sure whether or not a nodule has been sampled. I am generally reluctant to involve emphysema as a cause of respiratory embarrassment based on open lung biopsy, but the emphysema and mucus plugs are quite prominent in this case.

Thank you for referring this case in consultation. Please keep me informed of any follow-up and call if you have questions. With best wishes,

Sincerely yours,

Eugene J. Mark, M.D. 

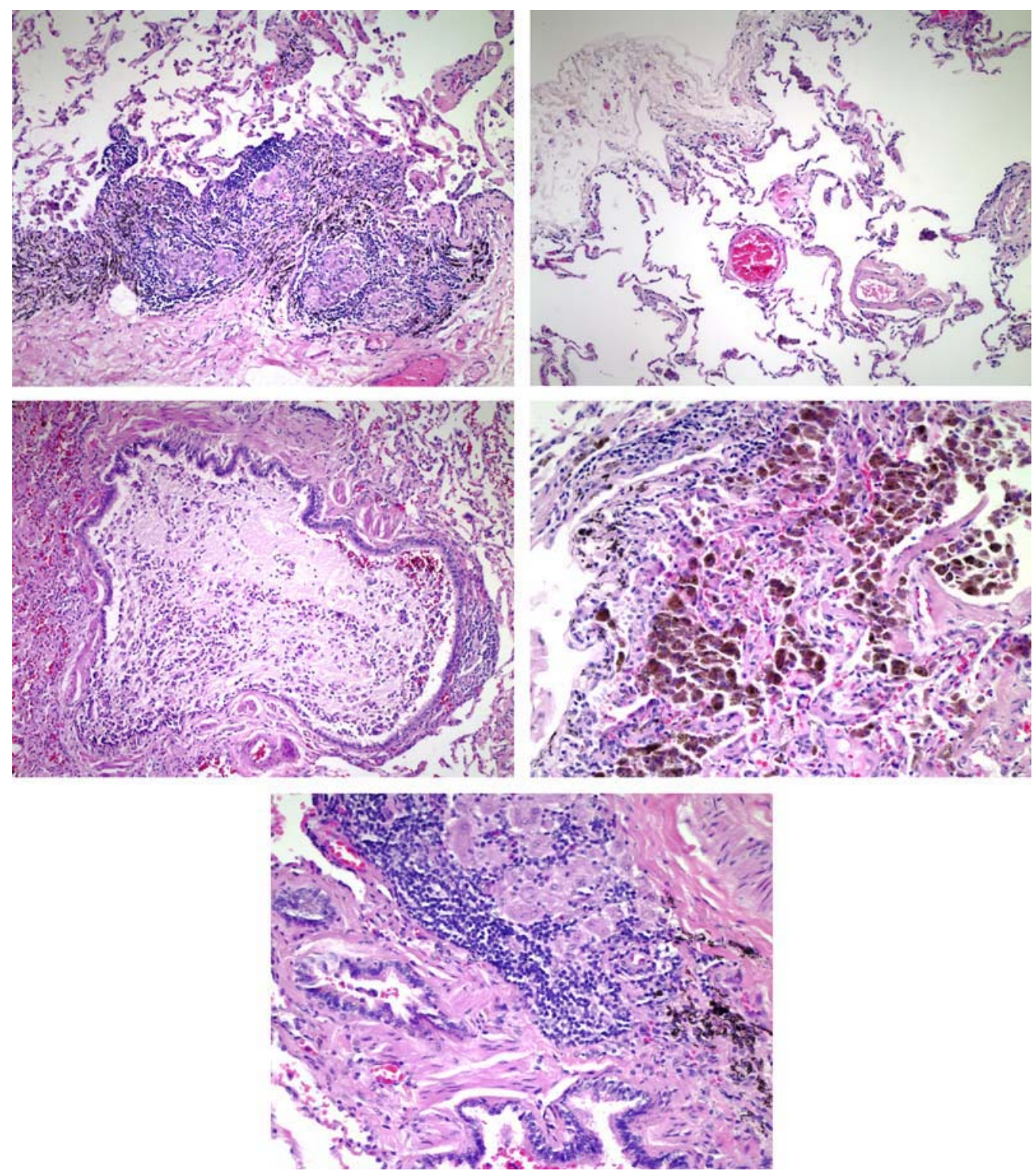

Case 6603 (Chapter 7 - Miscellaneous Pulmonary Disease) 


\section{Case 6816}

\section{Diagnosis: Lung, open biopsy: Lymphoproliferative disorder, benign, with ele- ments of follicular bronchiolitis and LIP.}

Lymphoid proliferation includes reactive follicles with central vessels and a lymphocytic infiltrate which lies to some degree along lymphangitic pathways (peribronhiolar and septal). The follicular lymphoid hyperplasia oriented around bronchioles can be described as follicular bronchiolitis. The lymphocytic interstitial infiltrate extending into alveolar septa can be described as resembling LIP. Because some of the lymphoid proliferations form nodules with invasion by lymphocytes of connective tissue planes, we considered the possibility of a low grade malignant lymphoma such as a malignant lymphoma of mucosa-associated lymphoid tissue (MALToma). However, the infiltrate is not as extensive as generally seen with MALTomas, and the centroblast-like cells characteristic of that disease are not evident (Giemsa stain). We also considered lymphoplasmacytic lymphoma, but periodic acid-Schiff stain shows no intranuclear Dutcher bodies. We performed immunopathological evaluation for B cells and light chains to demonstrate restriction. The follicles contain both $\mathrm{T}$ cells and $\mathrm{B}$ cells. The $\mathrm{B}$ cells express both kappa and lamda light chains. Thus, this histology does not satisfy criteria for a malignant lymphoma. I performed additional stains (elastic tissue, trichrome, Giemsa) to further evaluate the slides. The connective tissue stains accentuate the vascular pattern of follicular centers and suggest that they are normal and not neoplastic

I understand that the patient has mediastinal lymphadenopathy, pleural effusion, densities on chest radiograph with air bronchograms, splenomegaly, shortness of breath, and fever. Although these clinical features raise the possibility of malignant lymphoma, the biopsy does not substantiate that impression. Collagen-vascular disease, Sjogren's syndrome, and immunosuppressed states are conditions that can produce lymphoproliferative reactions as are present here.

Thank you for referring this case in consultation. Please keep me informed of any follow-up. This is a confirmation of my telephone call. Other pathologists in the department have reviewed the case and essentially concur with the above. With best wishes,

Sincerely yours,

Eugene J. Mark, M.D. 

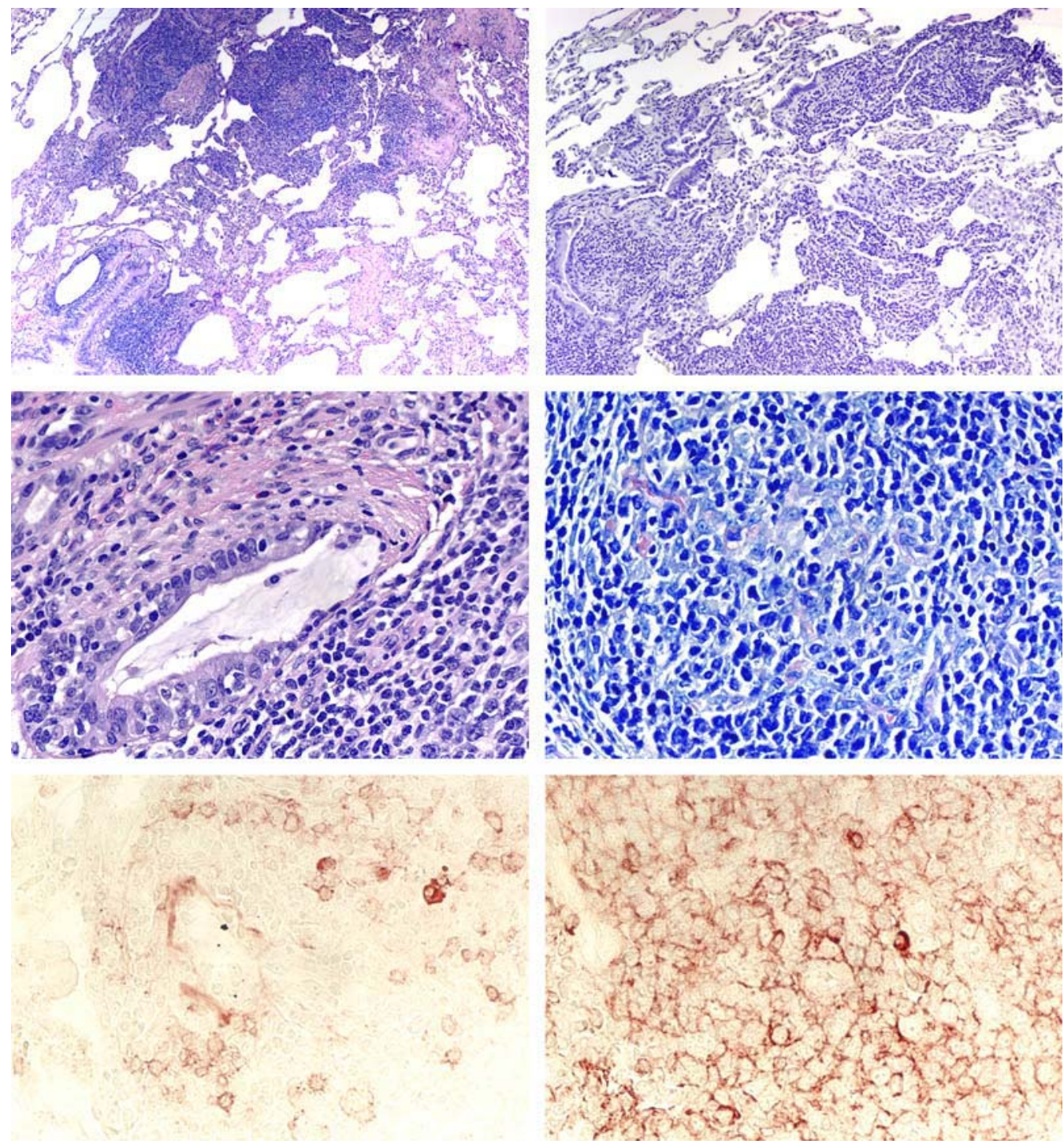

Case 6816 (Chapter 7 - Miscellaneous Pulmonary Disease) 


\section{Case 6618}

\section{Diagnosis: Lung, open biopsy: Lymphoid proliferation with sclerosis and oblit- erated bronchioles, consistent with Sjogren's syndrome.}

A modest proliferation of lymphocytes is oriented around blood vessels and a few remaining terminal bronchioles. Like you, I considered low grade lymphoma of lymphomatoid granulomatosis type because of the combination of lymphocytes and sclerosis, but I agree that the quantity of the infiltrate and the absence of atypia indicate that this is not a malignant lymphoma. It is always possible that malignant lymphoma will later develop in a patient with Sjogren's syndrome. This degree of lymphoid proliferation may be seen in Sjogren's syndrome, which is the interpretation I prefer. Some of the scarring is focal. Focal scarring and inflamed arteries are in part unaccompanied by bronchioles. Therefore, I believe there has been an obliteration of bronchioles, probably of the constrictive rather than intraluminal obliterative type. This is an unusual manifestation of Sjogren's syndrome, but follicular bronchiolitis is common.

Thank you for referring this case in consultation. A member of our hematopathology section has reviewed the case and essentially concurs with the above. Please keep me informed of any follow-up and call if you have questions.

Sincerely yours,

Eugene J. Mark, M.D.

\section{References:}

Deheinzelin D, Capelozzi VL, Kairalla RA, Barbas Filho JV, Saldiva PH, de Carvalho CR. Interstitial lung disease in primary Sjogren's syndrome. Clinical-pathological evaluation and response to treatment. Am J Respir Crit Care Med 1996;154:794-799.

Constantopoulos SH, Papadimitriou CS, Moutsopoulos HM. Respiratory manifestations in primary Sjogren's syndrome. A clinical, functional, and histologic study. Chest 1985;88:226-229.

Hansen LA, Prakash UB, Colby TV. Pulmonary lymphoma in Sjogren's syndrome. Mayo Clin Proc 1989;64:920-931.

Tsokos M, Lazarou SA, Moutsopoulos HM. Vasculitis in primary Sjogren's syndrome. Histologic classification and clinical presentation. Am J Clin Pathol 1987;88:26-31.

Provost TT, Talal W, Harley JB, Reichlin M, Alexander E. The relationship between anti-Ro (SS-A) antibody-positive Sjogren's syndrome and anti-Ro (SS-A) antibody-positive lupus erythematosus. Arch Dermatol 1988;124:63-71. 

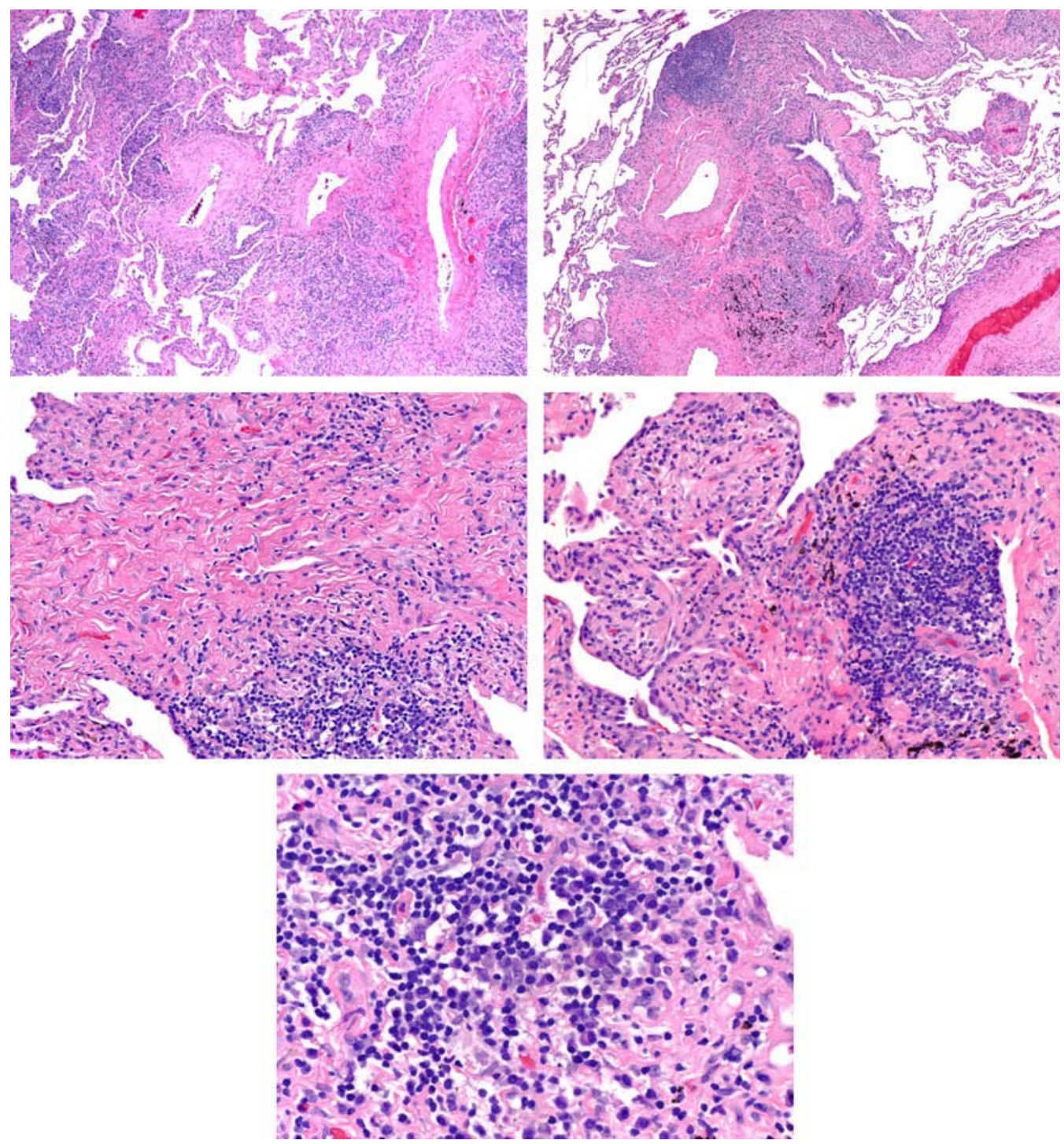

Case 6618 (Chapter 7 - Miscellaneous Pulmonary Disease) 


\section{Case 7004}

Diagnosis: Lung, open biopsy: Proliferation of clear epithelioid cells with marked PAS-positivity, type and significance uncertain, with focal sclerosis, ? unusual multifocal clear cell neuroendocrine proliferation, ? other.

I am not sure what this case represents. The epithelioid cells have clear cytoplasm and seem associated in part with vascular spaces. Our differential diagnosis is wide and includes lymphangioma, metastatic atrial myxoma, low grade intravascular sclerosing bronchoalveolar tumors, clear cell epithelioid leiomyomas or clear cell variant of lymphangioleiomyomatosis, and clear cell multifocal neuroendocrine proliferation. I would not make a diagnosis of malignancy in this case, firstly because I do not know what the lesion specifically is, secondly because there is no clinical evidence to support a malignant interpretation, and thirdly because there is no obvious treatment modality if this unusual process were called malignant. I considered an infectious etiology and, in particular, Whipple's disease and Mycobacterium avium/intracellulare. The acid-fast stain is negative. The PAS stain is markedly positive but without discernible organisms. This might support a diagnosis of a neuroendocrine cell proliferation with glycogen in a manner analagous to that which occurs in clear cell ("sugar") tumor. The biopsy also contains emphysema with small sclerotic and calcified scars.

Thank you for sharing this case with us. Please keep me informed of any follow-up. This is an elaboration of our telephone conversation.

Sincerely yours, Eugene J. Mark, M.D. 

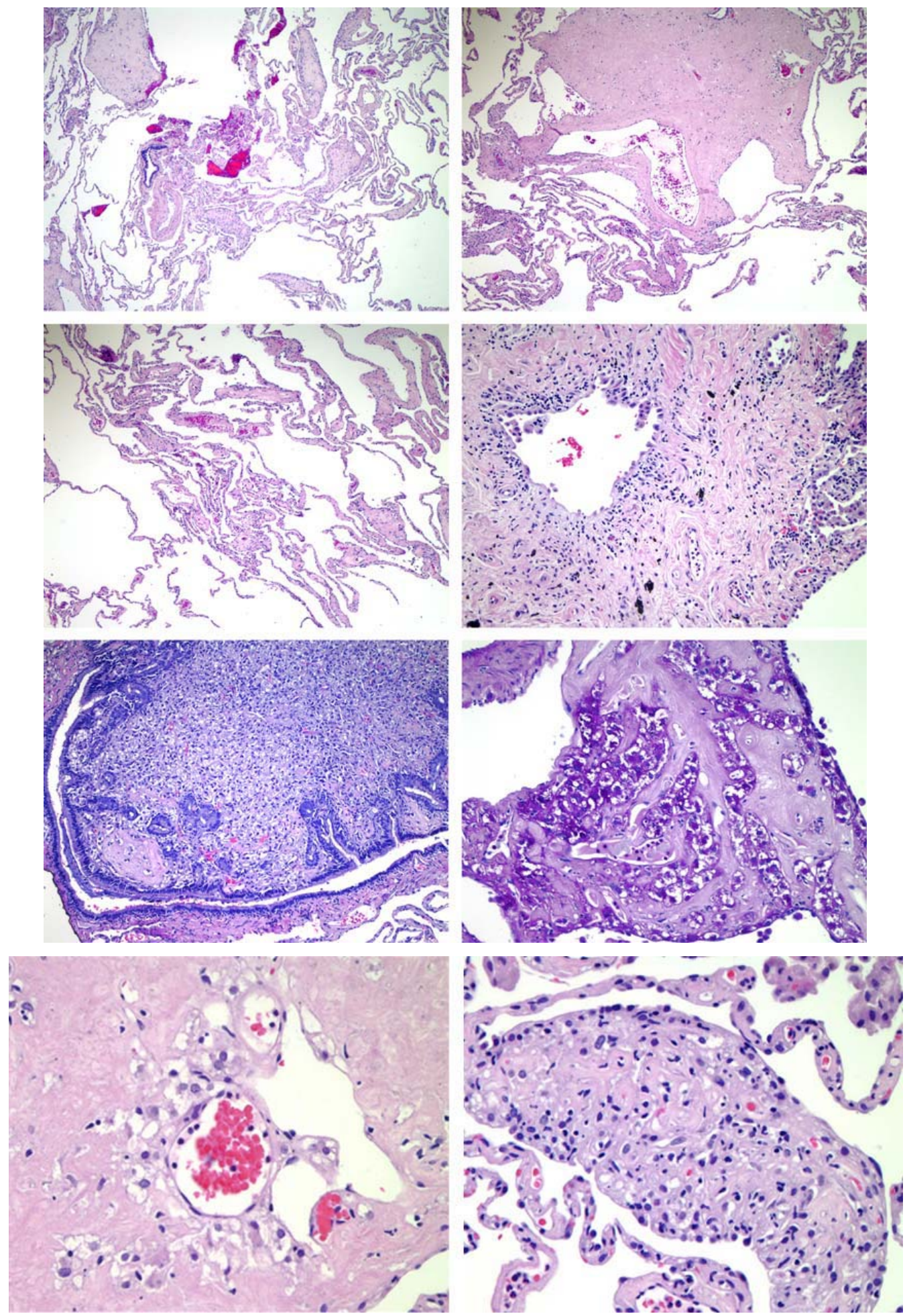

Case 7004 (Chapter 7 - Miscellaneous Pulmonary Disease) 


\section{Case 6667}

Diagnosis: Lung, open biopsy:

1. Interstitial cystic spaces, consistent with congenital cystic lymphangiectasia.

2. Immature lung, regional, consistent with cellular interstitial pneumonitis.

I have reviewed this case in conjunction with the clinical and radiographic features of the patient as presented by attending physicians and several other pulmonary pathologists at the Pediatric Pulmonary Rounds today. The above diagnoses best explain the patient's overall clinical course.

Sincerely yours,

Eugene J. Mark, M.D. 

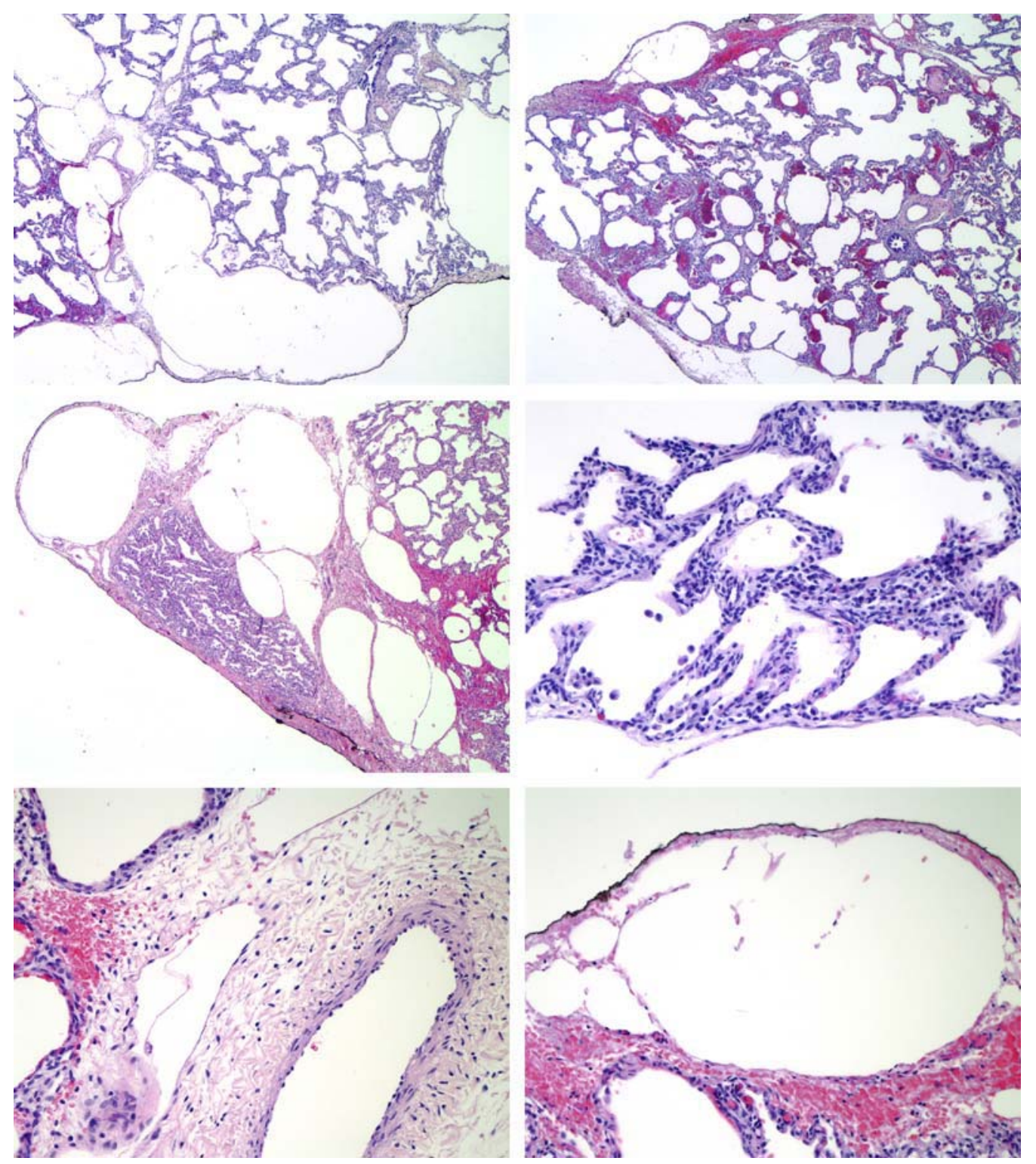

Case 6667 (Chapter 7 - Miscellaneous Pulmonary Disease) 


\section{Case 6869}

Diagnosis: Lung, wedge resection: Congenital cystic adenomatoid malformation, type II, with focal squamous metaplasia and hyperplasia, ? arising in a bronchial hamartoma.

This highly unusual lesion has both epithelial and mesenchymal elements. The epithelial elements include prominent papillarity, and the cells include both ciliated and nonciliated columnar epithelial cells. The mesenchyme is spindled and possibly smooth muscle in areas. The multifaceted low power appearance with cysts of varying size and a corrugated epithelium in regions indicates a congenital cystic adenomatoid malformation. The focal squamous metaplasia and hyperplasia are unusual. Occasionally cystic adenomatoid malformations arise in sequestrations. Rarely malignancies arise in cystic adenomatoid malformation, but there is no malignancy in this specimen. The outline of the nodule is like that of a bronchial hamartoma, and possibly this one has arisen in a hamartoma, which would be a new concept but not unlike that of origin in a sequestration. Papillary adenomas have a more monotonous and uniform appearance at low power magnification.

Thank you for referring this case in consultation. This is a confirmation of my telephone call. Please keep me informed of any follow-up. With best wishes,

Sincerely yours,

Eugene J. Mark, M.D. 

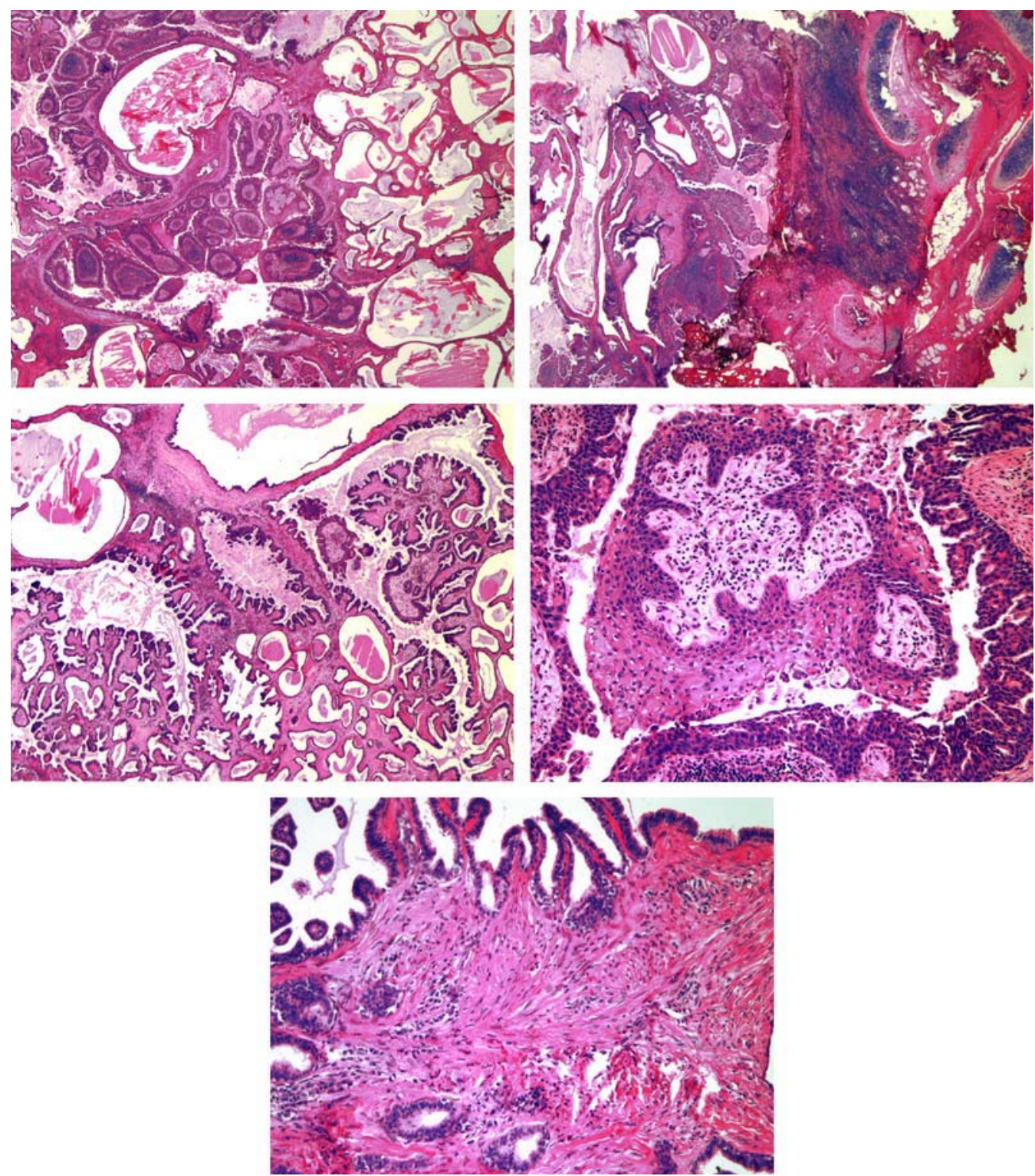

Case 6869 (Chapter 7 - Miscellaneous Pulmonary Disease) 


\section{Case 6809}

\section{Patient: 13-d-old male}

Diagnosis: Mass (periadrenal): Extralobar sequestration of the lung with congenital cystic adenomatoid malformation.

Histologically one sees relatively uniform bronchiolar structures lined by ciliated columnar epithelium associated with a primitive mesenchymal stroma and some more distal airspaces lined by flattened epithelium corresponding to alveolar ducts. The well structured composition is not what one expects in an extralobar sequestration, but it is in keeping with congenital cystic adenomatoid malformation. On the other hand, a congenital cystic adenomatoid malformation of the lung generally is not completely separated from the lung; nor does it lie beneath the diaphragm. So, a diagnosis of extralobar sequestration is appropriate as well. The large and relatively well-formed bronchus simulating a hilus is what one expects with sequestration and is very similar to the recent Case Records of the Massachusetts General Hospital. This is all very much in keeping with your interpretation. This is a very beautiful case. Thank you for sharing it with us.

I hope you have fond memories of your brief stay at the Massachusetts General Hospital. With best wishes,

Sincerely yours,

Eugene J. Mark, M.D. 

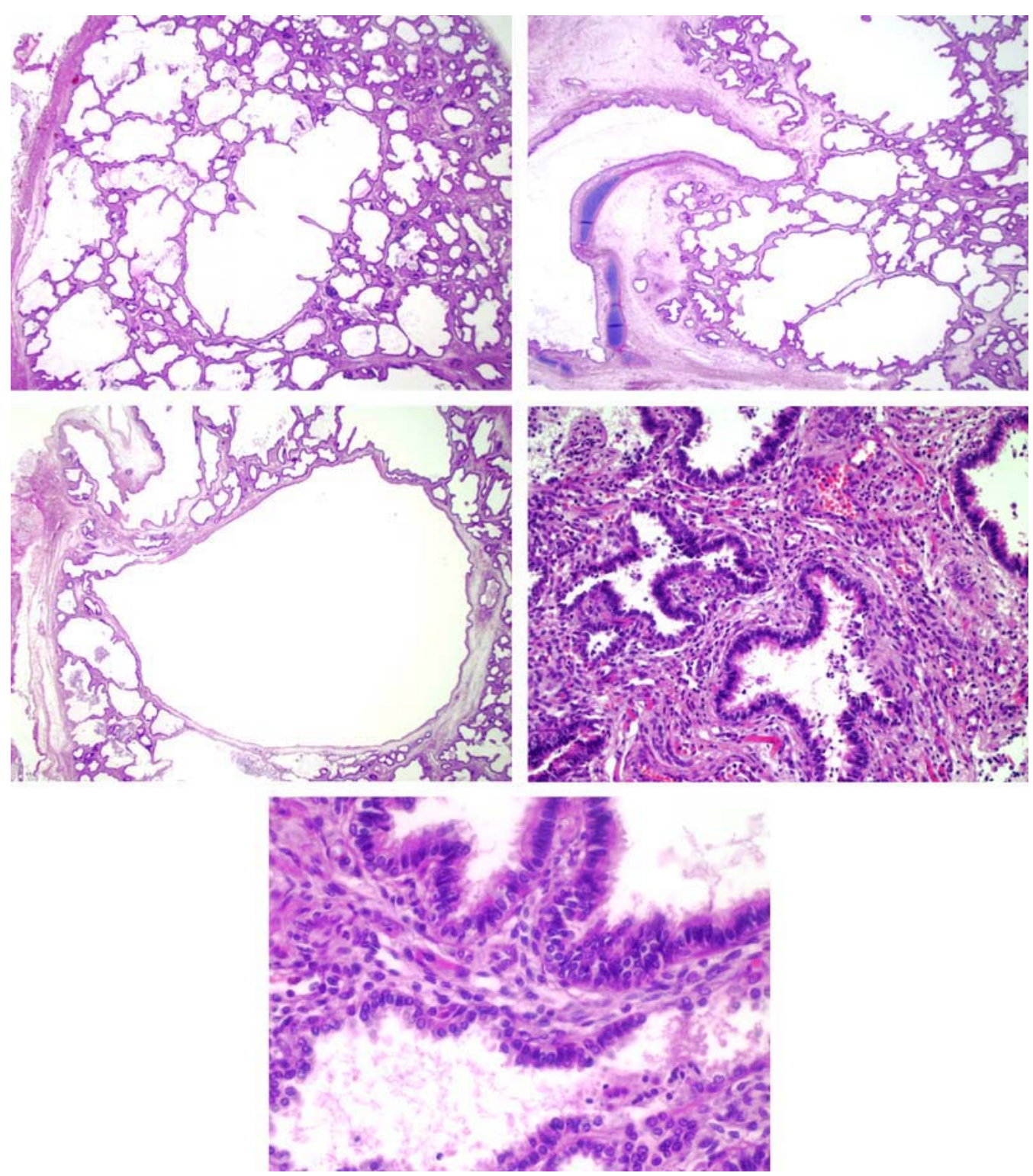

Case 6809 (Chapter 7 - Miscellaneous Pulmonary Disease) 


\section{Case 4408}

\section{Patient: 34-yr-old female}

Diagnosis: Lung, wedge resection: Cystic mesenchymal lesion, ? cystic mesenchymal hamartoma.

The low power configuration of a cyst lined by benign columnar epithelium and surrounded by a thin layer of proliferating spindle cells is consistent with a cystic mesenchymal hamartoma. However, the myxoid and vascular areas in the mesenchyme raise the possibility of a low-grade sarcoma, particularly a metastatic sarcoma from the uterus such as a low-grade leiomyosarcoma or stromal sarcoma. I cannot distinguish these two lesions histopathologically in this particular case.

Thank you for referring this case in consultation. Please keep me informed of any follow-up. With best wishes,

Sincerely yours, Eugene J. Mark, M.D. 

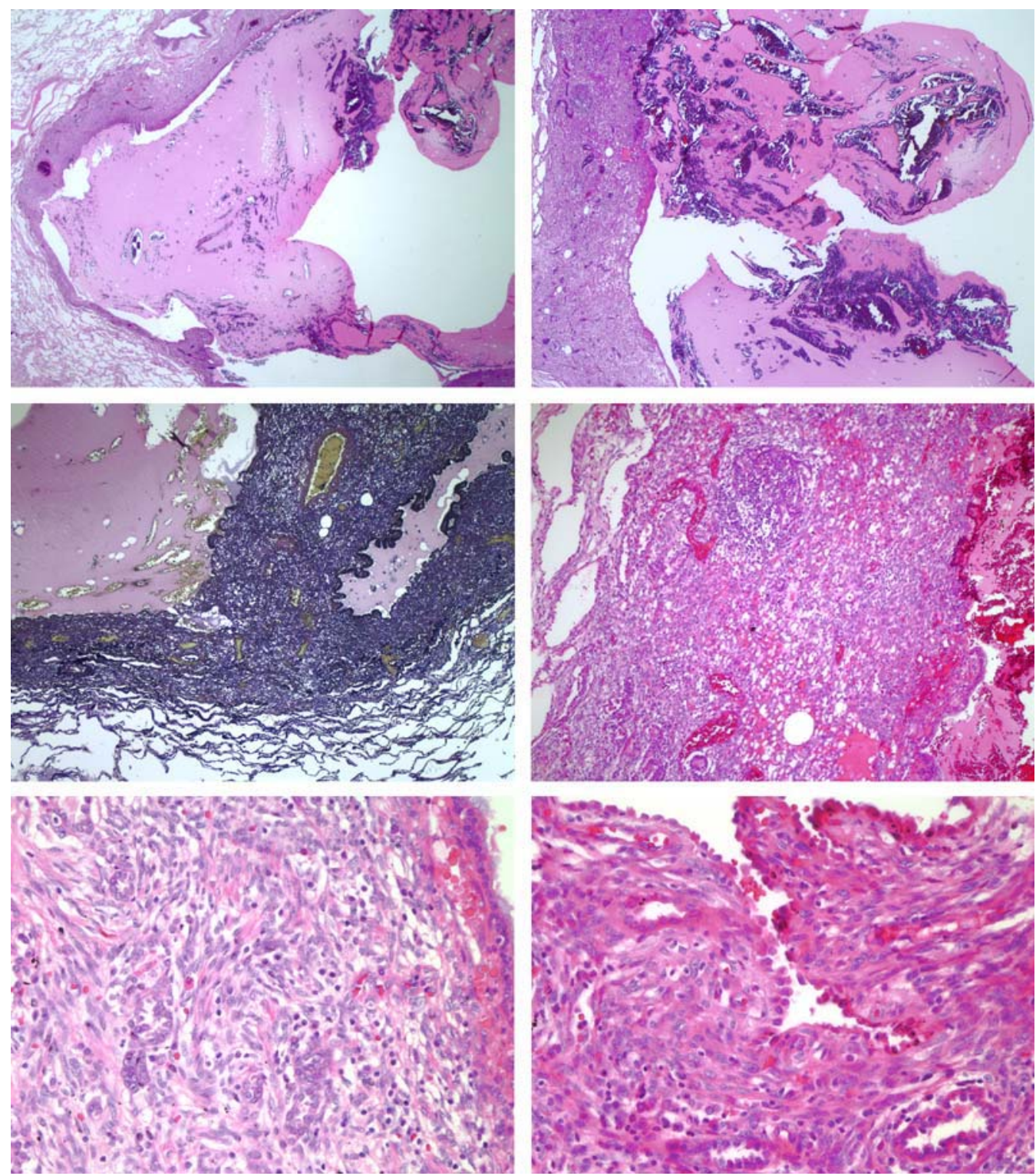

Case 4408 (Chapter 7 - Miscellaneous Pulmonary Disease) 